Document downloaded from:

http://hdl.handle.net/10251/78707

This paper must be cited as:

Benajes Calvo, JV.; Novella Rosa, R.; De Lima Moradell, DA.; Tribotté, P. (2015). Investigation on Multiple Injection Strategies for Gasoline PPC Operation in a Newly Designed 2-Stroke HSDI Compression Ignition Engine. SAE International Journal of Engines. 8(2):758-774. doi:10.4271/2015-01-0830.

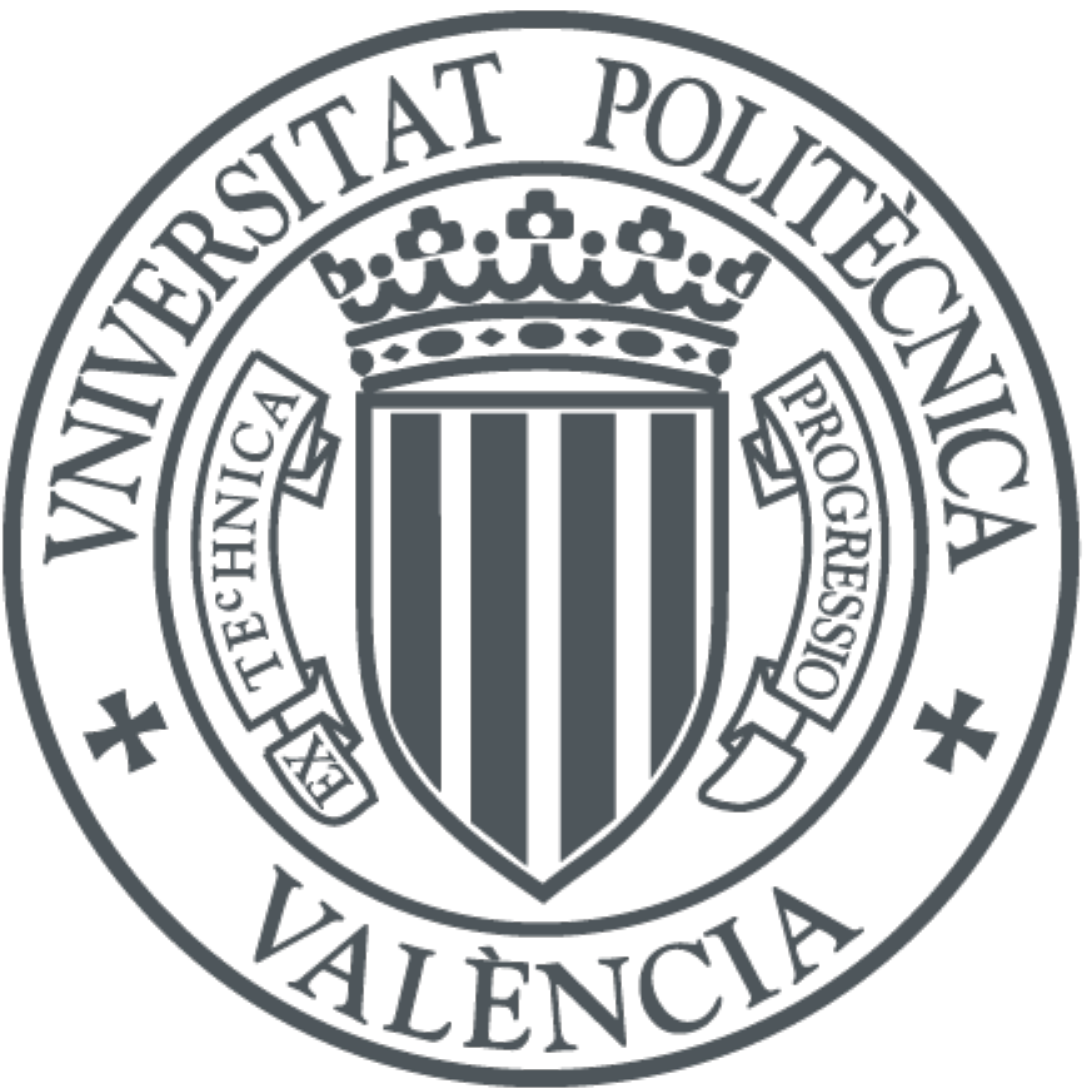

The final publication is available at

http://dx.doi. org/10.4271/2015-01-0830

Copyright SAE International

Additional Information 


\title{
Investigation on Multiple Injection Strategies for Gasoline PPC Operation in a Newly Designed 2-stroke HSDI Compression Ignition Engine
}

\author{
Jesus Benajes, Ricardo Novella, Daniela de Lima and Pascal Tribotté \\ Universitat Politècnica de València, CMT-Motores Térmicos
}

Pascal Tribotté

Renault SAS

\begin{abstract}
Partially Premixed Combustion (PPC) of fuels in the gasoline octane range has proven its potential to achieve simultaneous reduction in soot and $\mathrm{NO}$ x emissions, combined with high indicated efficiencies; while still retaining proper control over combustion phasing with the injection event, contrary to fully premixed strategies. However, gasoline fuels with high octane number as the commonly available for the public provide a challenge to ensure reliable ignition especially in the low load range, while fuel blends with lower octane numbers present problems for extending the ignition delay in the high load range and avoid the onset of knocking-like combustion. Thus, choosing an appropriate fuel and injection strategy is critical to solve these issues, assuring successful PPC operation in the full engine map.
\end{abstract}

In this framework, the objective of the present investigation consists of evaluating the use of multiple injection strategies for achieving stable PPC operation, attaining low $\mathrm{NO}_{\mathrm{x}}$ and soot emissions together with high efficiencies. This research was carried out in a singlecylinder DOHC 2-stroke HSDI CI engine using 95 Research Octane Number (RON) gasoline fuel. Three different operating conditions in terms of indicated mean effective pressure (IMEP) and speed were investigated: 3.1 bar IMEP and $1250 \mathrm{rpm}, 5.5$ bar IMEP and 1500 rpm and 10.4 bar IMEP and $1500 \mathrm{rpm}$. Parametric variations of injection timings, at different rail pressures and different fuel split between injections were experimentally performed to analyze the effect of the injection strategy over the combustion process, exhaust emissions and efficiency levels.

Experimental results confirm how using an appropriate injection strategy helps to achieve stable PPC operation in the selected operating conditions; with competitive combustion stability, lower $\mathrm{NO}_{\mathrm{x}}$ and soot levels, and moderate $\mathrm{CO}$ and $\mathrm{HC}$ emissions with combustion efficiency over $96 \%$, compared to Conventional Diesel Combustion (CDC).

Finally, a detailed analysis of the local cylinder conditions was performed by means of 3D-CFD simulations in order to provide guidelines for further optimization of the gasoline PPC concept, when using multiple injection strategies in the 2-stroke engine under development.

Page 1 of 16

\section{Introduction}

Conventional compression ignition (CI) engines are well known for their higher thermal efficiency compared to gasoline spark ignition (SI) engines. However, the characteristic mixing-controlled combustion stage of the Conventional Diesel Combustion (CDC) concept still represents an important source of nitrogen oxides (NOx) and also particulate matter pollutant emissions [1-5].

In the past decade, increasingly stringent pollutant emission regulations added to the need of decreasing $\mathrm{CO}_{2}$ emissions while also meeting customer's expectations regarding fuel consumption, has driven research efforts towards further increasing engine thermal efficiency while simultaneously reducing harmful exhaust emissions [6]. This has considerably accelerated the development process of established and new engine technologies, focused specially on aftertreatment and advanced combustion strategies for pollutant control, but also on decreasing mechanical and thermal losses for improving efficiency while increasing the specific power of modern combustion engines [7-9].

With this motivation, an innovative DOHC 2-stroke HSDI CI engine with scavenge loop through four poppet valves in the cylinder head is being developed for a heavily downsized passenger car application, where high power-to-weight ratio is mandatory. The idea behind this new engine concept is implementing a 2 -stroke cycle to downsize the displacement and obtain a two cylinder $\left(730 \mathrm{~cm}^{3}\right)$ engine with equivalent $\mathrm{NVH}$ and torque response than the base 4-stroke four cylinder engine [10].

Previous research carried out by the authors in a single-cylinder research version of this 2-stroke engine operating in CDC, confirmed that the engine architecture under study provides high flexibility in terms of air management settings, to control the cylinder conditions and affect combustion environment and final emissions level [11]. Furthermore, the Homogeneous Charge Compression Ignition (HCCI) combustion concept with diesel fuel was implemented at low load conditions, and its potential for simultaneous reductions of $\mathrm{NO}_{\mathrm{X}}$ and soot emissions was experimentally proven [12]. However, the high reactivity of diesel fuel added to the intrinsically high residual gas fraction (IGR), characteristic of the scavenge loop architecture; made it impossible to attain a properly-phased combustion process even when using optimized hardware and engine settings [13]. Therefore, the application of HCCI in this 2-stroke engine concept was discarded. 
Several problems commonly encountered when operating with HCCI and high cetane diesel fuels, can be alleviated by switching towards slightly retarded injection timings compared to those required to achieve a fully homogeneous mixture [14-19]. This approach, known as Premixed Compression Ignition (PCI) or Partially Premixed Combustion (PPC), was designed to operate CI engines in between fully premixed and fully diffusive combustion, where simultaneous reduction in NOx and soot emissions can be still attained, while retaining the control over the combustion timing by the injection event $[20,21]$.

The first strategies reported in the literature to achieve PPC with high cetane diesel fuels, were focused on a combination of high fractions of cooled EGR with comparatively low compression ratio; and/or high injection pressures combined with high swirl ratios to speed up the mixing process [20-23]. These strategies aim to extend the ignition delay for premixing the fuel-air charge as much as possible before combustion starts, avoiding over-rich regions where soot is formed; while $\mathrm{NO}_{\mathrm{x}}$ formation is decreased by reducing combustion temperatures due to the dilution effect of EGR. However, the operating range for simultaneous reduction of NOx and soot emissions is narrow and a sharp decline in combustion efficiency is often unavoidable.

Later, research work performed by Kalghatgi et al. both in heavyduty and light-duty size engines, demonstrated how gasoline-like fuels, having a higher resistance to auto-ignition, are better suited for extending mixing times before the onset of combustion compared to diesel-like fuels [24-26]. As a result, low values of engine-out soot and NOx emissions can be obtained in a wider range of loads compared to PPC of diesel fuels.

Since this early work, many research groups from Lund University [27-32], University of Cambridge [33], Argonne National Laboratory [34-36], University of Wisconsin Madison [37] and Delphi Corporation [38-40] have performed additional experimental and numerical investigations operating with PPC using different fuels in the octane range of gasoline and ethanol. Different injection strategies have been explored, with various EGR rates, boost pressures, intake temperatures and swirl ratios at different engine loads and speeds. In general, reported results confirmed how it is possible to implement PPC with very high efficiency, very low $\mathrm{NO}_{\mathrm{X}}$ emissions and also lower soot levels compared to CDC in a wide range of load operation.

During PPC operation, the reactivity of the fuel-air charge is mainly controlled by the ignition characteristics of the fuel, the cylinder thermo-chemical conditions, and the mixture stratification in terms of equivalence ratio prior to the start of combustion (SoC). For instance, gasoline fuels with high octane number $(\mathrm{ON})$ provide a challenge to ensure reliable ignition especially in the low load limit, while fuel blends with lower ON present problems for extending the ignition delay in the high load range and avoid the onset of knocking combustion. This supposes that the PPC concept requires different fuel reactivity and/or advanced valvetrain and boost/EGR systems to assure proper ignition control, and optimize emissions and efficiency in the full engine map [39]. Thus, there are still many practical issues which remain under investigation before reaching a production-viable powertrain; such as the injection system requirements, combustion chamber design, air charging strategy definition, among others.

In this framework, the flexibility of the 2-stroke architecture for assuring stable PPC operation in medium/low load conditions was already demonstrated by the authors using a single injection strategy

Page 2 of 16 with RON95 gasoline [41]. At 5 bar IMEP and 3 bar IMEP it was possible to achieve low NOx emissions (below $0.4 \mathrm{~g} / \mathrm{kWh}$ ) with extremely low soot emissions, while retaining $98 \%$ of combustion efficiency and proper combustion stability with a coefficient of variation $(\mathrm{CoV})$ in the IMEP under 3\%. However, at higher load (10 bar IMEP) a transition between premixed and mixing-controlled combustion was observed depending on the particular in-cylinder conditions, and the conventional trade-off between $\mathrm{NOx}$ and soot emissions was recovered [42].

Recent investigations have shown that the use of a multiple injection strategy allows precise control of the fuel-air stratification before the SoC, which affects the timing and strength of auto-ignition as well as the rate and completeness of fuel oxidation throughout the combustion chamber [35, 43-45]. Moreover, Sellnau et al. confirmed the potential of a triple injection strategy for increasing thermal efficiency compared to single injection strategies thanks to reduced heat losses during the expansion stroke given by a more favorable fuel distribution during combustion which results in less contact between hot combustion gases and chamber walls [38, 39].

As mentioned, combustion characteristics are highly dependent on the mixture preparation prior to ignition; therefore, both the timing and the fuel quantity injected in each injection must be carefully optimized depending on the operating condition. The objective of the present investigation focuses on evaluating the use of multiple injection strategies for achieving stable PPC operation in the singlecylinder 2-stroke CI engine using RON95 gasoline. Parametric variations of the timing of the main injection, with different rail pressures and different fuel split between injections were experimentally performed at three operating conditions, to analyze the effect of the injection strategy on the combustion process, exhaust emissions and efficiency levels.

\section{Experimental Setup}

\section{Engine architecture and test cell characteristics}

Experimental activities were performed in the single-cylinder research version of an innovative Renault engine concept, consisting of a two-cylinder DOHC 2-stroke HSDI CI engine with scavenge loop, which is currently under development.

The combustion chamber has four poppet valves with doubleoverhead camshafts and a staggered roof geometry, specifically designed for masking the flow of air between the intake and exhaust valves, allowing proper scavenging of the burnt gases while keeping short-circuit losses as low as possible during 2-stroke operation. The definition of the engine architecture, boost system requirements, combustion chamber geometry and scavenging characteristics of this newly designed engine were reported by the authors in previous publications $[10,46]$.

A hydraulic cam-driven Variable Valve Timing system allows delaying intake and exhaust valve timings with a cam phasing authority of +30 degrees from base timing, as it was detailed in a previous investigation $[41,42]$. In this research, the key valve timing angles (EVO/EVC/IVO/IVC) were defined at those crank angle degrees $(\mathrm{CAD})$ where the given valve lift was $0.3 \mathrm{~mm}$. The single cylinder research version of the Renault 2-stroke engine concept has been manufactured by Danielson. As a reference, Table 1 lists detailed engine specifications. 


\begin{tabular}{|l|l|}
\hline Engine type & 2-stroke compression ignition \\
\hline Displacement & $365 \mathrm{~cm} 3$ (single cylinder) \\
\hline Bore $\times$ Stroke & $76 \mathrm{~mm} \times 80.5 \mathrm{~mm}$ \\
\hline Connecting Rod Length & $133.75 \mathrm{~mm}$ \\
\hline Compression ratio & $17.6: 1$ \\
\hline Number of Valves & $4(2$ intake \& 2 exhaust) \\
\hline Type of scavenge & Poppet valves with scavenge loop \\
\hline Valvetrain & DOHC with VVA \\
\hline $\begin{array}{l}\text { Nominal intake valve timing (set at } \\
\text { VVT=0) }\end{array}$ & $\begin{array}{l}\text { IVO }=161.9 \text { CAD aTDC } \\
\text { IVC }=251.6 \text { CAD aTDC }\end{array}$ \\
\hline $\begin{array}{l}\text { Nominal exhaust valve timing (set at } \\
\text { VVT=0) }\end{array}$ & $\begin{array}{l}\text { EVO=122.6 CAD aTDC } \\
\text { EVC }=226.9 \text { CAD aTDC }\end{array}$ \\
\hline Fuel injection system & Diesel common rail HSDI \\
\hline Injector nozzle & $148^{\circ}$ AN, 8 holes, 90 $\mu \mathrm{m}$ \\
\hline
\end{tabular}

\begin{tabular}{|l|l|}
\hline Test fuel & Unleaded gasoline with lubricity additive \\
\hline Research Octane Number (RON) & 94.6 \\
\hline Motor Octane Number (MON) & 84.8 \\
\hline H/C ratio & $1.76 \mathrm{~mol} / \mathrm{mol}$ \\
\hline O/C ratio & $0 \mathrm{~mol} / \mathrm{mol}$ \\
\hline Aromatics & $36.1 \% \mathrm{Vol}$ \\
\hline Benzene & $0.3 \% \mathrm{Vol}$ \\
\hline Oxygen content & $<0.17 \%(\mathrm{~m} / \mathrm{m})$ \\
\hline (A/F)St (by mass) & 14.37 \\
\hline LHV & $42.82 \mathrm{MJ} / \mathrm{kg}$ \\
\hline Density $\left(15^{\circ} \mathrm{C}\right)$ & $758.1 \mathrm{~kg} / \mathrm{m}^{3}$ \\
\hline Kinematic viscosity $\left(40^{\circ} \mathrm{C}\right)$ & $0.44 \mathrm{cSt}$ \\
\hline
\end{tabular}

The single-cylinder engine is very flexible and parts can be easily interchanged. However, for this first evaluation of the PPC concept, a conventional diesel piston with geometric compression ratio equal to 17.6 and wide angle injector nozzle non-optimized for the strategy were kept on the engine. The injection system is a common rail HSDI designed for injecting diesel up to a maximum rail pressure of 1800 bar. The injector is equipped with a 8 holes nozzle, with hole diameter of $90 \mu \mathrm{m}$ and a spray cone angle of $148^{\circ}$. A detailed optimization operating with the PPC concept is expected to provide a better piston/nozzle match in terms of number of holes, hole diameter, spray included angle and bowl geometry.

The injector mass flow rate and spray momentum flux were measured in a dedicated test rig at a suitable range of operating conditions in terms of injection pressure, injector back-pressure and injection duration; following the methodology described in $[47,48]$ using commercial diesel fuel and also the selected gasoline fuel. The maximum injection pressure when injecting gasoline is limited to 1200 bar, to avoid cavitation in the return line and assure correct measurement of the fuel flow. However, in the conditions studied in this research, extremely high injection pressures are not expected to be interesting, since lower pressures help reducing the tendency for spray impingement on surfaces of the combustion chamber. A lubricity additive was added to the RON95 gasoline, in a small proportion compared to the total blend, to ensure proper operation of the injection equipment without affecting the ignition characteristics of the gasoline. Most important fuel properties are listed in Table 2.

The single-cylinder engine test cell is equipped with independent water and oil cooling circuits, an external compressor unit with its dryer for providing water-free compressed air to simulate the required boosting conditions, and an additional low pressure EGR circuit to provide arbitrary levels of cooled EGR even at high intake pressures. The fuel consumption of the engine is measured with an accuracy of $0.2 \%$ using a gravimetric dynamic fuel meter. Measurements of $\mathrm{O}_{2}, \mathrm{CO}, \mathrm{CO}_{2}, \mathrm{HC}, \mathrm{NO}_{\mathrm{x}}, \mathrm{N}_{2} \mathrm{O}$, and EGR rate are performed for all the tests with a state-of-the-art HORIBA 7100 DEGR gas analyzer. Soot emissions traced by the filter smoke number (FSN) are measured with an AVL 415 Smokemeter.

The laboratory setup used in the experimental test campaign, as well as the required instrumentation and the accuracy of most important measurement equipment, were fully described in previous publications $[41,42]$.

Page 3 of 16

The trapping ratio is defined as the mass of delivered charge that has been trapped in the cylinder at IVC divided by the mass of delivered charge supplied to the cylinder (fresh air plus EGR). It is measured experimentally in every point of the test matrix by means of a tracer gas method $[49,50]$, using methane $\left(\mathrm{CH}_{4}\right)$ as external gas. First, a controlled quantity of $\mathrm{CH}_{4}$ (around $1000 \mathrm{ppm}$ ) is homogenously injected in the intake flow, when operating at the stabilized point with the desired engine settings. Next, the $\mathrm{CH}_{4}$ concentration is measured at the intake and also at the exhaust manifolds with a dedicated analyzer. Assuming that all the $\mathrm{CH}_{4}$ trapped in the cylinder will burn completely during combustion, an accurate estimation of the shortcircuited mass from the intake flowing directly to the exhaust is obtained by means of a set of mass balances in the intake, exhaust and in-cylinder gases.

The internal gas recirculation (IGR) ratio is then defined as the fraction of residual gases retained from the previous combustion cycle in the total trapped mass in the cylinder. The IGR ratio, total trapped mass at IVC and in-cylinder effective equivalence ratio ( $\phi_{\text {eff }}$ ) are estimated in each measured test using simplified thermodynamic calculations. This estimation is based on an enthalpy balance, where the enthalpy of the total trapped mass at the IVC equals to the enthalpy of the residual mass plus the enthalpy of the intake delivered trapped mass, both estimated also at the IVC

It can be presumed that the air management characteristics are not affected by the negligible change in the combustion process that could be derived from the addition of the tracer gas, when is injected in such a small proportion. However, for accurate measurement of the exhaust emissions and precise combustion diagnosis, all the required instantaneous signals and time-averaged measurements are performed after the trapping ratio has been measured, thus, after removing the injection of tracer gas in the intake flow.

Cylinder pressure is measured using a piezoelectric sensor, while a different piezorresistive pressure sensor is placed at the cylinder liner close to the bottom dead center to reference the piezoelectric sensor signal. All high frequency signals are sampled with a resolution of 0.2 CAD. Main global combustion parameters like indicated mean effective pressure (IMEP), peak cylinder pressure $\left(\mathrm{P}_{\max }\right)$, maximum pressure gradient $\left(\mathrm{dP} / \mathrm{da}_{\mathrm{max}}\right)$ and combustion stability indicators $(\mathrm{CoV}$ IMEP and CoV $\mathrm{P}_{\max }$ ) are directly derived from the analysis of the cylinder pressure signal. An in-house combustion analysis software (CALMEC) is used to resolve the first law of thermodynamics and obtain the instantaneous evolution of the energy released by the 
progress of combustion from the measured pressure signal. Then, the start of combustion (SoC), combustion angles (CA10, CA50, CA90), ignition delay and mixing times are obtained from the calculated rate of heat release (RoHR). The RoHR calculation includes sub-models for considering heat transfer losses, mechanical deformation of the cylinder and blow-by losses.

Finally, combustion noise has been calculated following the classical approach introduced by Austen and Priede [51]. The classical approach is frequently used by engine development engineers to assess the overall engine combustion noise level at steady operating conditions $[52,53]$. This method is based on calculating the 'structural attenuation' curve, which is the difference between the cylinder pressure and the radiated noise 1/3-octave band spectra. In this theory, since a linear response of the engine structure is assumed, its characteristic attenuation curve can be used as a transfer function to estimate the sound pressure level spectrum of the engine noise from the cylinder pressure trace.

\section{Multi-dimensional engine model}

A computational fluid dynamic (CFD) model was built in the CONVERGE CFD platform to perform full coupled open and closed cycle calculations using the full intake/exhaust and cylinder geometries. The CFD code uses a structured Cartesian grid with base cell size of $3 \mathrm{~mm}$. Three additional grid refinements linked to flow velocity and temperature were performed by means of an adaptive mesh refinement (AMR) as well as a fixed three level refinement within the spray region.

The injection rate profile was generated from the experimental database available after the injector characterization. The diesel-like injection of gasoline is simulated by the standard Discrete Droplet Model (DDM) [54]. Gasoline fuel physical properties are defined using iso-octane as surrogate. Spray atomization and break-up are simulated by means of the Kelvin-Helmholtz-Rayleigh-Taylor (KHRT) model [55]. Turbulent flow is modeled by means of the renormalization group (RNG) $\mathrm{k}-\varepsilon$ model with wall functions in order to account for wall heat transfer [56]. Concerning combustion modeling, a direct integration of detailed chemistry approach was used by means of the CONVERGE code and the SAGE solver.

The chemical mechanism of a primary reference fuel (PRF) blend of n-heptane (5\%) and iso-octane (95\%) is used as fuel surrogate to reproduce the ignition characteristic of the RON95 gasoline. A wellvalidated skeletal reaction mechanism for PRF oxidation derived from the ERC-Multichem mechanism [57], with 45 species and 152 reactions was used for the fuel chemistry representation. In particular, the mechanism includes the thermal path for $\mathrm{NO}_{\mathrm{x}}$ formation according to the extended Zeldovich mechanism, and the $\mathrm{N}_{2} \mathrm{O}$ path for accounting the $\mathrm{NO}_{\mathrm{x}}$ formation at low temperatures, where this path gains relevance. A classical 2-step phenomenological soot model is used, with the Hiroyasu soot formation mechanism combined with a Nagle-Strickland-Constable (NSC) model for soot oxidation $[58,59]$.

The full description of the model setup performed at the reference case with 10.4 bar IMEP and $1500 \mathrm{rpm}$ operating with the gasoline PPC concept and the three injection strategy was described in detail in a previous publication [44].

\section{Methodology}

The research work, divided into the three different load points described below, corresponds to basic studies of the gasoline PPC concept, without in-depth optimization of the engine hardware or settings. The engine operating conditions chosen for this experimental test campaign correspond to one low speed/load point, at $1250 \mathrm{rpm}$ and $3.1 \mathrm{bar}$ of IMEP; and two low speed and medium load points, at $1500 \mathrm{rpm}$ and 5.5 and 10.4 bar IMEP respectively.

A dedicated Design of Experiment (DoE) campaign, using a Central Composite Design with four factors and five levels, was previously performed in the engine, to optimize the air management conditions using response surface models for different engine outputs (such as fuel consumption or emissions), while operating in $\mathrm{CDC}$ at the selected operating points $[11,44]$. The intake pressure $\left(\mathrm{P}_{\text {int }}\right)$, the EGR rate, the pressure difference between the intake and exhaust $(\Delta \mathrm{P})$, and the valve overlap (Olap) are the four air management settings selected as input factors in the DoE. The resulting second order mathematical models were used to find proper in-cylinder conditions, mainly in terms of oxygen concentration $\left(\mathrm{YO}_{2}, \mathrm{IVC}\right)$ and temperature at IVC ( $\left.\mathrm{T}_{\mathrm{IVC}}\right)$, to assure proper ignition around TDC when operating with the PPC concept.

A multiple injection strategy (triple or double injection) was used in all studies presented in this research, with a fixed fueling rate which provided the required IMEP target at the baseline case with the optimum CA50 at each load. The total injected quantity was kept constant for all tests along the different studies. Then, the injection timing of the main injection, which is the one primarily controlling combustion onset, was swept each $2 \mathrm{CAD}$ for each study; in a range defined considering the onset of knocking combustion or smoke limit and the deterioration of combustion stability as the main constraints.

For medium-to-high load points (as in the case of 10.4 bar IMEP), a triple injection strategy is expected to help in achieving the load target while avoiding/mitigating knock tendency, as in the case of medium load operation (5.5 bar IMEP) both triple and double injections are evaluated in order to find the most suitable injection pattern. Finally, in the case of the lower load condition (3.1 bar IMEP), a double injection strategy was selected in advance, since a relatively small fuel quantity is injected. So, the $1^{\text {st }}$ early injection placed at $-60 \mathrm{CAD}$ aTDC is removed, to avoid excessively high $\mathrm{HC}$ emissions, and the fuel is split between the remaining two injections.

The influence of the injection pressure $\left(\mathrm{P}_{\text {rail }}\right)$ and fuel split between the injections (\%fuel) is evaluated at the medium load points (5.5 and 10.4 bar IMEP), aside from the straight effect of sweeping the injection timing of the main injection. Specifically in the case of the low load point (3.1 bar IMEP), it was only possible to measure two different \%fuel at one level of injection pressure. At this low load condition, the high resistance to auto-ignition given by the RON95 gasoline increases the sensitivity of the combustion process to the injection strategy.

Oil and coolant temperatures were kept at $90^{\circ} \mathrm{C}$, while intake air temperature $\left(\mathrm{T}_{\mathrm{int}}\right)$ was carefully controlled during all tests by using a heater. The injection timing is referred to the Start of Energizing (SoE) current of the injector instead the actual Start of Injection (SoI), which happens a few degrees (1.5 to $2 \mathrm{CAD}$ ) after the SoE due to the hydraulic delay affecting the needle lift. The most relevant engine settings chosen for each operating condition are detailed below in Table 3 . 
Table 3: Engine settings for experiments at a) $1500 \mathrm{rpm}-10.4$ bar IMEP, b) $1500 \mathrm{rpm} 5.5$ bar IMEP and c) $1250 \mathrm{rpm}$ and 3.1 bar IMEP

\begin{tabular}{|c|c|c|c|c|c|c|}
\hline \multicolumn{7}{|c|}{$1500 \mathrm{rpm} / 10.4$ bar IMEP } \\
\hline $\begin{array}{c}\text { Air } \\
\text { management }\end{array}$ & $\begin{array}{c}T_{\text {int }} \\
{\left[{ }^{\circ} \mathrm{C}\right]} \\
\end{array}$ & $\begin{array}{c}P_{\text {int }} \\
\text { [bar] }\end{array}$ & $\begin{array}{c}\Delta P \\
{[\text { bar] }}\end{array}$ & $\begin{array}{l}V V T_{(I, 2)} \\
{[C A D]} \\
\end{array}$ & $\begin{array}{c}\text { Olap } \\
{[C A D]}\end{array}$ & $\begin{array}{l}E G R \\
{[\%]} \\
\end{array}$ \\
\hline ALL TESTS & 35 & 2.75 & 0.71 & $(5,20)$ & 78.4 & 43.5 \\
\hline $\begin{array}{l}\text { Injection } \\
\text { process }\end{array}$ & $\begin{array}{c}m_{f u e l} \\
{[\mathrm{mg} / \mathrm{st}]}\end{array}$ & $\begin{array}{c}P_{\text {rail }} \\
\text { [bar] }\end{array}$ & $\begin{array}{c}S o E 1 \\
{[C A D]}\end{array}$ & $\begin{array}{c}\text { SoE2 } \\
{[C A D]}\end{array}$ & $\begin{array}{c}\text { SoE3 } \\
{[C A D]}\end{array}$ & $\begin{array}{c}\% \text { fuel } \\
{[\%]}\end{array}$ \\
\hline Baseline & 18.8 & 850 & -60 & $-42 /-34$ & -2 & $20 / 64 / 16$ \\
\hline$P_{\text {rail }}=750$ bar & 18.8 & 750 & -60 & $-44 /-38$ & -2 & $20 / 64 / 16$ \\
\hline$P_{\text {rail }}=950$ bar & 18.8 & 950 & -60 & $-38 /-34$ & -2 & $20 / 64 / 16$ \\
\hline$\%$ fuel $=20 / 69 / 11$ & 18.8 & 850 & -60 & $-44 /-40$ & -2 & $20 / 69 / 11$ \\
\hline$\%$ fuel $=20 / 56 / 24$ & 18.8 & 850 & -60 & $-38 /-34$ & -2 & $20 / 56 / 24$ \\
\hline
\end{tabular}

\begin{tabular}{|c|c|c|c|c|c|c|}
\hline \multicolumn{7}{|c|}{1500} \\
\hline $\begin{array}{c}\text { Air } \\
\text { management }\end{array}$ & $\begin{array}{c}T_{i n t} \\
{\left[{ }^{\circ} \mathrm{C}\right]}\end{array}$ & $\begin{array}{c}P_{\text {int }} \\
\text { [bar] }\end{array}$ & $\begin{array}{c}\Delta P \\
{[\text { bar] }}\end{array}$ & $\begin{array}{l}V V T_{(1,2)} \\
{[C A D]}\end{array}$ & $\begin{array}{c}\text { Olap } \\
{[C A D]}\end{array}$ & $\begin{array}{l}E G R \\
{[\%]}\end{array}$ \\
\hline ALL TESTS & 45 & 1.7 & 0.32 & $(8,8)$ & 63.4 & 33.5 \\
\hline $\begin{array}{l}\text { Injection } \\
\text { process }\end{array}$ & $\begin{array}{c}m_{\text {fuel }} \\
{[\mathrm{mg} / \mathrm{st}]}\end{array}$ & $\begin{array}{c}P_{\text {rail }} \\
\text { [bar] }\end{array}$ & $\begin{array}{c}\text { SoE1 } \\
{[C A D]}\end{array}$ & $\begin{array}{c}S o E 2 \\
{[C A D]}\end{array}$ & $\begin{array}{c}\text { SoE3 } \\
{[C A D]}\end{array}$ & $\begin{array}{c}\text { \%fuel } \\
{[\%]}\end{array}$ \\
\hline Baseline & 10.8 & 600 & -60 & $-42 /-34$ & -4 & $16 / 68 / 16$ \\
\hline$P_{\text {rail }}=400 \mathrm{bar}$ & 10.8 & 400 & -60 & $-46 /-38$ & -4 & $16 / 68 / 16$ \\
\hline$P_{\text {rail }}=800$ bar & 10.8 & 800 & -60 & $-40 /-34$ & -4 & $16 / 68 / 16$ \\
\hline$\%$ fuel $=0 / 84 / 16$ & 10.8 & 600 & w/o & $-46 /-38$ & -4 & $0 / 84 / 16$ \\
\hline$\%$ fuel $=0 / 68 / 32$ & 10.8 & 600 & w/o & $-48 /-40$ & -4 & $0 / 68 / 32$ \\
\hline$\%$ fuel $=16 / 84 / 0$ & 10.8 & 600 & -60 & $-46 /-40$ & w/o & $16 / 84 / 0$ \\
\hline$\%$ fuel=16/68/0 & 10.8 & 600 & -60 & $-46 /-40$ & w/o & $32 / 68 / 0$ \\
\hline
\end{tabular}

\begin{tabular}{|c|cccccc|}
\hline \multicolumn{7}{|c|}{ c) $1250 \mathbf{~ r p m} / \mathbf{3 . 1}$ bar IMEP } \\
\hline $\begin{array}{c}\text { Air } \\
\text { management }\end{array}$ & $\begin{array}{c}T_{\text {int }} \\
{\left[{ }^{\circ} \mathrm{C}\right]}\end{array}$ & $\begin{array}{c}P_{\text {int }} \\
{[\text { bar }]}\end{array}$ & $\begin{array}{c}\Delta P \\
{[\text { bar }]}\end{array}$ & $\begin{array}{c}V V T_{(l, 2)} \\
{[C A D]}\end{array}$ & $\begin{array}{c}\text { Olap } \\
{[C A D]}\end{array}$ & $\begin{array}{c}E G R \\
{[\%]}\end{array}$ \\
\hline ALL TESTS & 45 & 1.295 & 0.21 & $(14,13)$ & 62.4 & 15 \\
\hline Injection & $m_{\text {fuel }}$ & $P_{\text {rail }}$ & SoE1 & SoE2 & SoE3 & $\%$ fuel \\
process & {$[m g / s t]$} & {$[$ bar $]$} & {$[C A D]$} & {$[C A D]$} & {$[C A D]$} & {$[\%]$} \\
\hline \%fuel=0/60/40 & 6.5 & 400 & w/o & $-36 /-26$ & -4 & $\mathbf{0 / 6 0 / 4 0}$ \\
\%fuel=0/40/60 & 6.5 & 400 & w/o & $-40 /-30$ & -4 & $\mathbf{0 / 4 0 / 6 0}$ \\
\hline
\end{tabular}

\section{Results and Discussion}

Focusing on the air management characteristics, Table 3 summarizes the main settings selected for the injection studies. The goal is to control the in-cylinder conditions, by balancing both the trapping ratio and the amount of residual hot gases (IGR ratio), to search for conditions with high air trapped mass, which allow using the high EGR rates needed to decrease $\mathrm{NOx}$ emissions and control the combustion rate. In addition, the requirements in combustion stability are assured by affecting the temperature at the beginning of the closed cycle. Previous research work focused on the implementation of the PPC concept using a single injection strategy in the current 2stroke engine, already demonstrated the flexibility for controlling oxygen concentration ( $\mathrm{YO}_{2}$,IVC) and temperature (TIVC) at the IVC by using EGR, $\Delta \mathrm{p}$ and valve overlap as main control levers [41].

At the higher load point (10.4 bar IMEP), where temperatures are inherently high, the introduction of high rates of EGR (43.5\%) is mandatory for decreasing $\mathrm{YO}_{2, \mathrm{IVC}}$. This requires an intake pressure of 2.75 bar, 0.71 bar of $\Delta \mathrm{P}$, and an overlap of $78.4 \mathrm{CAD}$. With these settings, the air management parameters correspond to $67 \%$ of trapping ratio, $35 \%$ of IGR ratio, 0.83 of $\phi$ eff, and $12 \%$ and $168^{\circ} \mathrm{C}$ of $\mathrm{YO}_{2, \mathrm{IVC}}$, and $\mathrm{T}_{\mathrm{IVC}}$ respectively. The low oxygen concentration at IVC is necessary to avoid the onset of knocking-like combustion, reduce

Page 5 of 16
NOx emissions by decreasing combustion temperatures, and also to extend the ignition delay until reaching the mixing times needed to decrease soot emissions. The air management characteristics remained constant along the performed parametric tests, due to their weak relation with the injection settings.

When decreasing the engine load, decreasing $\Delta \mathrm{P}$ and valve overlap is mandatory to increase the IGR ratio and then TIVC until reaching the auto-ignition temperature of the RON95 gasoline (around 950 K) close to TDC and sustain the combustion process. Moreover, the combustion process becomes more sensitive and less tolerant to high EGR rates, so both the intake temperature and $\mathrm{T}_{\text {IVC }}$ are used to compensate the overall decrease in charge reactivity. At the medium load point (5.5 bar IMEP), the decrease in valve overlap and $\Delta \mathrm{P}$ to 63.4 CAD and 0.32 bar, made possible to increase trapping ratio and IGR ratio to $82 \%$ and $43 \%$, which added to a relatively high $\mathrm{P}_{\text {int }}$ and EGR of 1.7 bar and $33.5 \%$, resulted in $12 \%$ of $\mathrm{YO}_{2, \mathrm{IVC}}$ with $220^{\circ} \mathrm{C}$ of TIVC and 0.8 of $\phi_{\text {eff. }}$.

Finally, at the lower load point (3.1 bar IMEP) the main priority was to achieve stable PPC operation and assure reliable ignition. The chosen air management settings provided a trapping ratio/IGR combination of $81 \%$ and $54 \%$ respectively, while the EGR level is limited to $15 \%$ to maintain high combustion stability. The final incylinder conditions at this low load operation correspond to 0.66 of $\phi_{\text {eff, and }} 13.8 \%$ and $235^{\circ} \mathrm{C}$ of $\mathrm{YO}_{2, \mathrm{IVC}}$ and $\mathrm{T}_{\mathrm{IVC}}$ respectively. This intrinsic flexibility of the 2-stroke engine architecture is a key advantage to achieve PPC conditions over a wide operating range and assure stable combustion even at low loads, where auto-ignition of high octane fuels can be difficult in conventional 4-stroke engines.

Regarding the combustion process, Figure 1 shows the effect of the second injection timing, denoted as SoE2, over the RoHR profile for the three operating conditions at the baseline or reference study. The range of SoE2 is limited by poor combustion stability and misfire in the case of early timings, and by the onset of knocking-like combustion or smoke level above $4 \mathrm{FSN}$ in the case of late timings.

As described in a previous investigation performed at medium-tohigh load conditions using a triple injection strategy, the timing of the $2^{\text {nd }}$ injection is controlling both start of combustion (SoC) and phasing, while the timing of the $3^{\text {rd }}$ injection controls combustion rate and duration, but has a very small influence in the onset of combustion [44].

Figure 2 illustrates the effect of SoE2 over the SoC, and over combustion phasing traced by the angle at $50 \%$ of the mass burnt fraction (CA50) for the three operating conditions.

In the case of medium/high load conditions (5.5 bar and 10.4 bar IMEP), combustion onset and phasing shift towards the expansion stroke when advancing SoE2, while the RoHR becomes smoother with longer duration and lower peak, as confirmed by Figure 1. On the contrary, retarding SoE2 closer to TDC decreases ignition delay and mixing time, so the local equivalence ratio stratification increases enhancing the reactivity of the mixture. Consequently, SoC and CA50 advance towards the TDC, while combustion is faster with a higher peak in the RoHR. 
a) $\mathbf{N}=1500 \mathrm{rpm} /$ IMEP = 10.4 bar
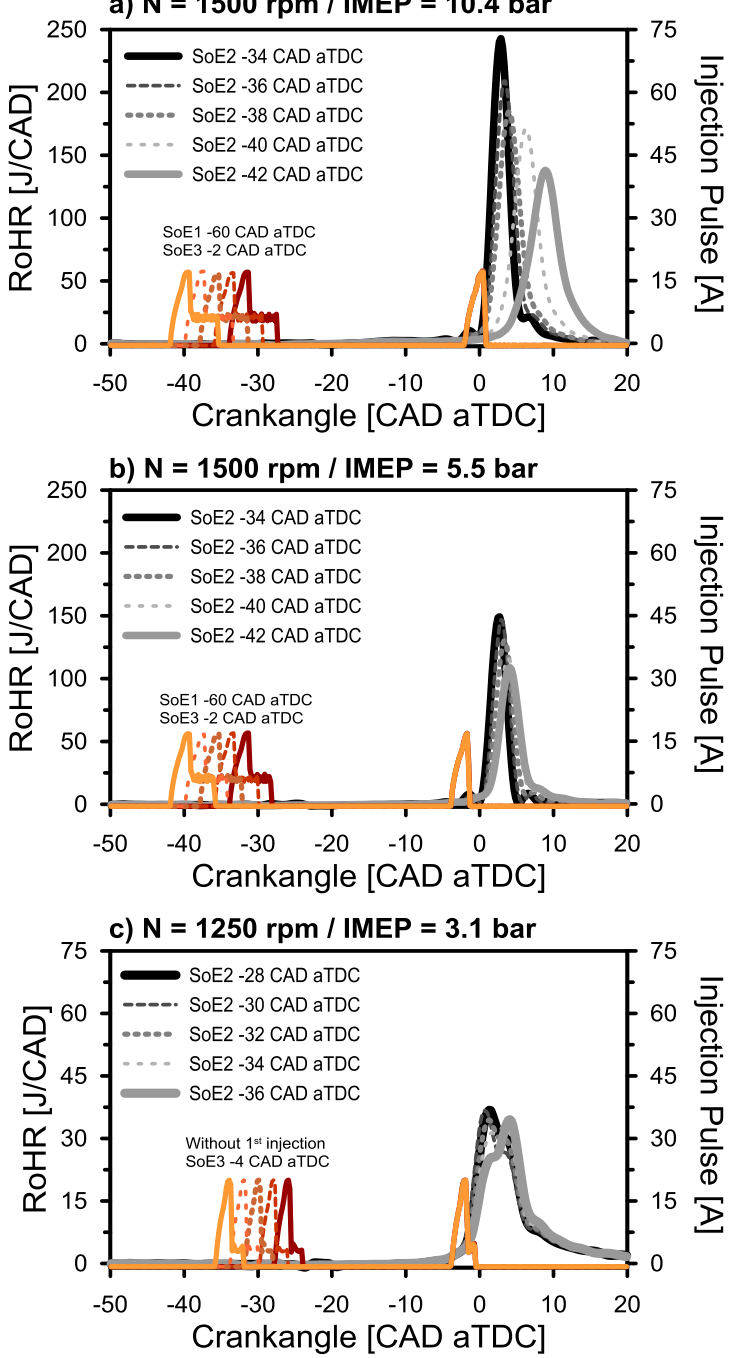

Figure 1: Effect of SoE2. RoHR and injection pulse for a) N=1500 rpm / IMEP=10.4 bar Baseline, b) N=1500 rpm / IMEP=5.5 bar Baseline and c) $\mathrm{N}=1250 \mathrm{rpm} / \mathrm{IMEP}=3.1 \mathrm{bar} \%$ fuel $=0 / 60 / 40$ case.

At the lower load point (3.1 bar IMEP) the RoHR exhibits a combined structure, with an initial premixed phase followed by a mixing-controlled stage, as shown in Figure 1.c. The stratification in local $\phi$, given by the relatively retarded SoE2 and higher fuel amount in the late injection close to TDC, allows assuring higher combustion stability and proper control over CA50 compared to a highly premixed combustion. Since a higher percentage of the fuel is injected in the late injection, the observed effect of SoE2 over the SoC and CA50 become less influential compared to the medium/high load cases, as confirmed by Figure 2.c, while the effect of the late injection (not presented in this investigation) starts to gain relevance.

Figure 3 shows the combustion noise and the coefficient of variation of the maximum cylinder pressure ( $\left.\mathrm{CoV} \mathrm{P}_{\max }\right)$ as an indicator of the combustion stability, as function of SoE2. In general terms, retarding CA50 later in the expansion stroke by advancing SoE2 allows

decreasing the maximum pressure gradient and combustion noise, as expected from the trends already observed in the RoHR.
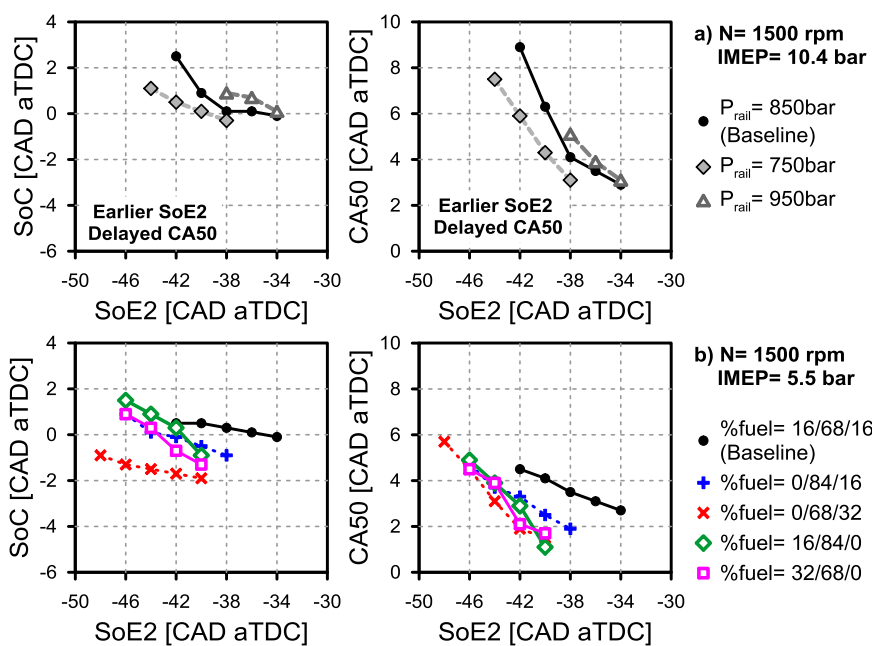

b) $\mathrm{N}=1500 \mathrm{rpm}$ IMEP $=\mathbf{5 . 5}$ bar

$\%$ fuel $=16 / 68 / 16$ - (Baseline)

$+\%$ fuel $=0 / 84 / 16$

$\times \%$ fuel $=0 / 68 / 32$

\%fuel= $16 / 84 / 0$

口 \%fuel $=32 / 68 / 0$
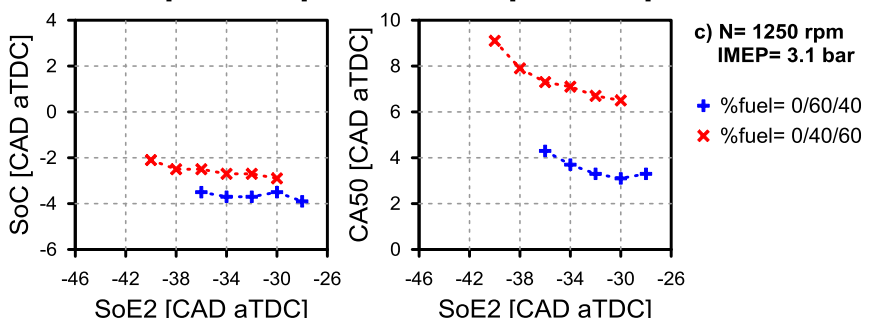

Figure 2: Effect of injection settings over combustion onset (SoC) and phasing (CA50) for a) $\mathrm{N}=1500 \mathrm{rpm} / \mathrm{IMEP}=10.4 \mathrm{bar}, \mathrm{b}) \mathrm{N}=1500 \mathrm{rpm} / \mathrm{IMEP}=5.5 \mathrm{bar}$ and c) $\mathrm{N}=1250 \mathrm{rpm} / \mathrm{IMEP}=3.1$ bar.

At the medium load points (5.5 and 10.4 bar IMEP) excessively high noise levels even over $100 \mathrm{~dB}$ are reported when approaching to knocking-like operation, due to the sharp and fast RoHR profile, reaching $\mathrm{dP} / \mathrm{da}_{\max }$ values of $20 \mathrm{bar} / \mathrm{CAD}$ which are not feasible for a production engine. On the contrary, retarding CA50 later in the expansion stroke by advancing SoE2 allows decreasing noise and $\mathrm{dP} / \mathrm{da}_{\max }$ down to $93 \mathrm{~dB}$ and $10 \mathrm{bar} / \mathrm{CAD}$ respectively for the baseline case of 10.4 bar IMEP, and $95 \mathrm{~dB}$ and $10.7 \mathrm{bar} / \mathrm{CAD}$ for the baseline case of 5.5 bar IMEP. Focusing on the lower load point (3.1 bar IMEP), both noise and $\mathrm{dP} / \mathrm{da}_{\max }$ levels are kept at a reasonably low range, going from 80 to $77 \mathrm{~dB}$ and from 5 to 2 bar/CAD respectively, mainly because the combustion process always combines a first premixed phase and a final mixing-controlled stage.

In terms of combustion stability, the coefficient of variation of the IMEP (CoV IMEP) was kept below a limit of $2.5 \%$ in all the measured tests and it showed a fairly constant trend with respect to the injection timing at the three different load conditions. However, advancing SoE2 earlier in the compression stroke increased the cycle-to-cycle dispersion in the cylinder pressure close to TDC, which was translated in a rise in $\mathrm{CoV} \mathrm{P}_{\max }$, as it is shown in Figure 3.b, even when CoV IMEP was not substantially affected.

Moreover, a limit was observed in terms of the latest CA50 measured at each SoE2 variation from which cyclic dispersion was rapidly increased, up to a point where it was not possible to sustain combustion and misfire cycles started to appear. This limit is strongly dependent on the particular in-cylinder thermochemical conditions. 

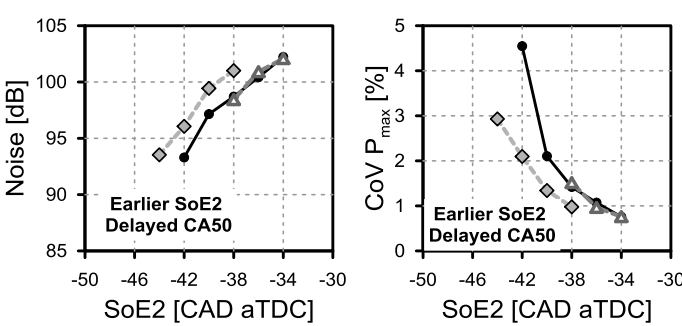

a) $\mathrm{N}=1500 \mathrm{rpm}$
IMEP= 10.4 bar

- $\mathrm{P}_{\text {rail }}=850 \mathrm{bar}$

- (Baseline)

$\diamond \mathrm{P}_{\text {rail }}=750$ bar

$\Delta P_{\text {rail }}=950$ bar
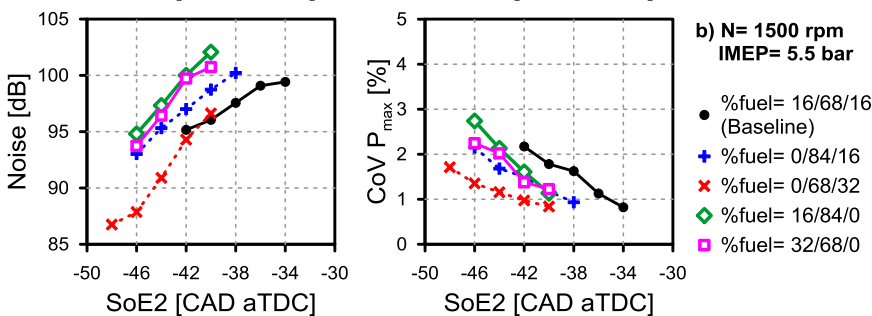

SoE2 [CAD aTDC]
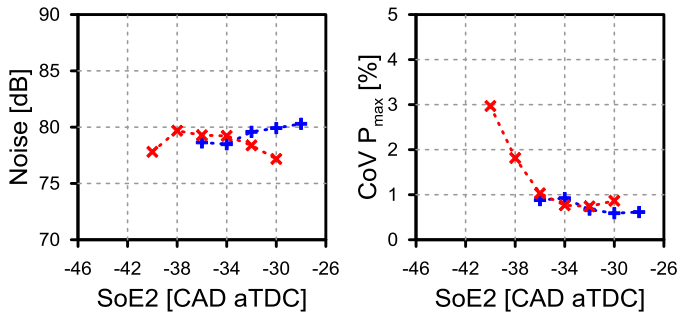

c) $\mathrm{N}=1250 \mathrm{rpm}$ IMEP= 3.1 bar

$+\%$ fuel $=0 / 60 / 4$ $\times \%$ fuel $=0 / 40 / 60$

Figure 3: Effect of injection settings over the Noise and CoV $\mathrm{P}_{\max }$ for a) $\mathrm{N}=1500 \mathrm{rpm} / \mathrm{IMEP}=10.4 \mathrm{bar}, \mathrm{b}) \mathrm{N}=1500 \mathrm{rpm} / \mathrm{IMEP}=5.5 \mathrm{bar}$ and c) $\mathrm{N}=1250 \mathrm{rpm} / \mathrm{IMEP}=3.1 \mathrm{bar}$.

Concerning exhaust emissions, previous investigation performed by the authors demonstrated how the NOx/soot trade-off is avoided during PPC operation when the combustion process (thus SoC and CA50) is retarded into the expansion stroke by advancing the second injection earlier during the compression stroke [44]. In the case of NOx emissions, the thermal $\mathrm{NO}_{\mathrm{x}}$ formation is decreased when advancing SoE2, as a result of lower combustion temperature given by the low $\mathrm{YO}_{2}$ added to the retarded and slower combustion process; while soot formation is decreased due to the extended mixing times before the SoC. However, when SoE2 is advanced enough so the fuel spray starts to be partially injected outside the bowl, the spray/wall interaction within the piston crown and squish area added to the lower combustion temperatures, worsens the fuel energy conversion and oxidation processes, consequently increasing $\mathrm{CO}$ and $\mathrm{HC}$ emissions. This is translated into a trade-off between $\mathrm{NO}_{\mathrm{X}} / \mathrm{soot}$ reduction and the deterioration of combustion efficiency ( $\left.\eta_{\text {combustion }}\right)$ for the early SoE2 cases.

Figure 4 confirms the effect of SoE2 over $\mathrm{NOx}$ and smoke emissions at the three operating conditions. In general, very low NOx and soot emissions can be achieved in the three different operating conditions while keeping $\eta_{\text {combustion }}$ over $96 \%$. At medium/high load conditions (5.5 bar and 10.4 bar IMEP) NOx emissions can be decreased down to $0.2 \mathrm{~g} / \mathrm{kWh}$ while smoke emissions are decreased below the minimum detection limit of the smoke meter for the points with early SoE2. At the lower load condition (3.1 bar IMEP) NOx level is slightly increased to $0.5 \mathrm{~g} / \mathrm{kWh}$ due to less tolerance to EGR, while smoke ranges between 0.2-0.3 FSN for the points with earlier SoE2.

For ease of understanding and to simplify the graphic representation, the effect of the injection pressure $\left(\mathrm{P}_{\text {rail }}\right)$ is shown only for the medium/high load point with 10.4 bar IMEP, while the effect of different fuel split among the injections (\%fuel) is shown at the medium/low load points with 5.5 and 3.1 bar IMEP.
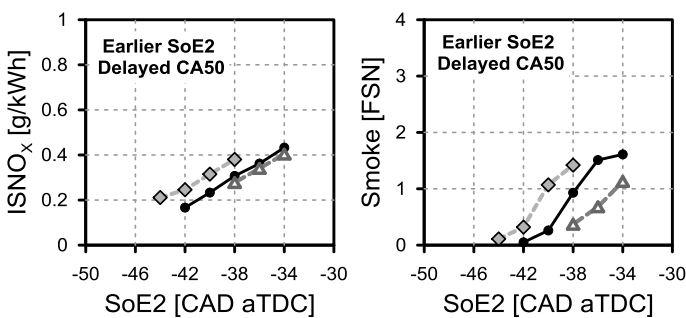

a) $\mathrm{N}=1500 \mathrm{rpm}$ IMEP= 10.4 bar

$\mathrm{P}_{\text {rail }}=850 \mathrm{bar}$

- (Baseline)

$\Delta P_{\text {rail }}=750$ ba

$\Delta P_{\text {rail }}=950$ bar
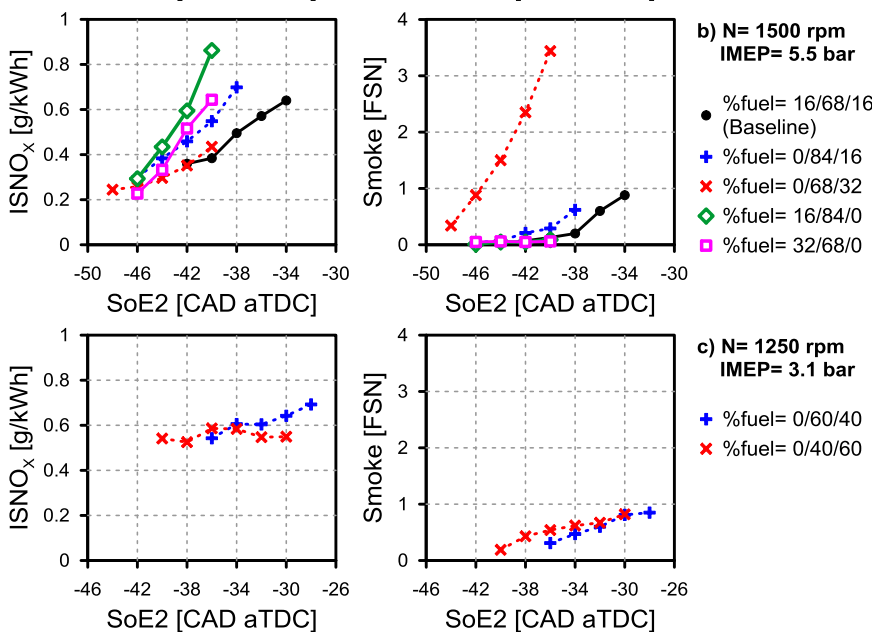

c) $\mathrm{N}=1250 \mathrm{rpm}$

$+\%$ fuel $=0 / 60 / 40$

$\times \%$ fuel $=0 / 40 / 60$

Figure 4: Effect of injection settings over $\mathrm{NO}_{\mathrm{X}}$ and smoke emissions for a) $\mathrm{N}=1500 \mathrm{rpm} / \mathrm{IMEP}=10.4 \mathrm{bar}, \mathrm{b}) \mathrm{N}=1500 \mathrm{rpm} / \mathrm{IMEP}=5.5 \mathrm{bar}$ and $\mathrm{c}$ ) $\mathrm{N}=1250 \mathrm{rpm} / \mathrm{IMEP}=3.1 \mathrm{bar}$

Focusing on the effect of injection pressure, slowing the mixing process by decreasing Prail to 750 bar brought an increase in the overall mixture reactivity, causing an advance in SoC and CA50 when compared against the baseline at constant SoE2, as confirmed by Figure 2.a for the higher load point. As a result, the noise level, shown in Figure 3.a, is increased by the earlier combustion phasing, as it was expected. At $P_{\text {rail }} 750$ bar the latest SoE2 was limited to -38 CAD aTDC to avoid the onset of knocking-like combustion and excessively high pressure gradients. Finally, Figure 4.a shows how smoke emissions are increased when decreasing $\mathrm{P}_{\text {rail }}$ as a consequence of shorter mixing time and worsened mixing conditions of the fuel injected in the late injection, which locally increases rich $\phi$ zones where soot formation occurs; while $\mathrm{NO}_{\mathrm{x}}$ also increases due to the faster combustion process, caused by the more reactive local $\phi$ distribution generated by the worsened mixing conditions also for the early injected fuel.

On the contrary, increasing $\mathrm{P}_{\text {rail }}$ to 950 bar allowed delaying both SoC and CA50 later into the expansion stroke, providing an important reduction in smoke emissions and also a slight reduction in $\mathrm{NOx}$ emissions as confirmed by Figure 4.a. However, it also shortened the window of operation between misfire and knock, limiting the range in terms of SoE2. The same trends are also observed at the medium load case (5.5 bar IMEP) and therefore, it can be concluded how increasing $\mathrm{P}_{\text {rail }}$ is an interesting option for improving the PPC performance in terms of $\mathrm{NOx} /$ soot, but this also reduces its operating range, so a detailed optimization is mandatory.

For the medium load point (5.5 bar IMEP) four different studies were performed using a double injection strategy, in order to show the effect of different fuel splits between injections and to compare them against the triple injection strategy used in the baseline case. First, the $1^{\text {st }}$ injection placed at $-60 \mathrm{CAD}$ aTDC was removed, and its fuel mass was relocated in the $2^{\text {nd }}$ injection $(\%$ fuel $=0 / 84 / 16)$ and in the $3^{\text {rd }}$ 
injection (\%fuel=0/68/32). Similarly, the $3^{\text {rd }}$ injection at $-4 \mathrm{CAD}$ aTDC was removed and its mass was added firstly in the $2^{\text {nd }}$ injection (\%fuel $=16 / 84 / 0)$ and secondly in the $1^{\text {st }}$ injection (\%fuel=32/68/0).

Figure 2.b confirms how removing either the $1^{\text {st }}$ or the $3^{\text {rd }}$ injection resulted in an increase in mixture reactivity that advanced both the SoC and the CA50 earlier in the cycle, enhancing the trend towards knocking-like combustion compared to the baseline case.

The RoHR profiles obtained at medium load (5.5 bar IMEP) for the two fuel splits measured when removing the $1^{\text {st }}$ injection (\%fuel 0/84/16 and 0/68/32) are included in Figure 5. The analysis is performed in two different conditions, first, keeping constant SoE2 at $-40 \mathrm{CAD}$ aTDC to evaluate the isolated effect of the fuel split, and then choosing the cases with CA50 equal to 4.5 CAD aTDC.

The RoHR profiles for SoE2 -40 CAD aTDC shown in Figure 5.a confirm how the combustion advances when the $1^{\text {st }}$ injection is removed and its fuel is introduced either in the $2^{\text {nd }}$ or in the $3^{\text {rd }}$ injection. This trend appeared to be caused by slight differences in the temperature evolution along the compression stroke, considering that the cooling effect generated by the evaporation of the fuel is modified for each injection pattern. In the case of $\%$ fuel $=0 / 84 / 16$, the RoHR is faster with a higher peak due to higher reactivity at SoC resulting from the shorter time to premix the fuel added in the $2^{\text {nd }}$ injection. Focusing on \%fuel=0/68/32 where the injection pattern promotes the $3^{\text {rd }}$ injection close to TDC, the peak of the RoHR is lower and combustion duration is longer compared to \%fuel $=0 / 84 / 16$ even when combustion starts slightly earlier. This confirms the reduction of the premixed phase and the extension of the mixingcontrolled stage.
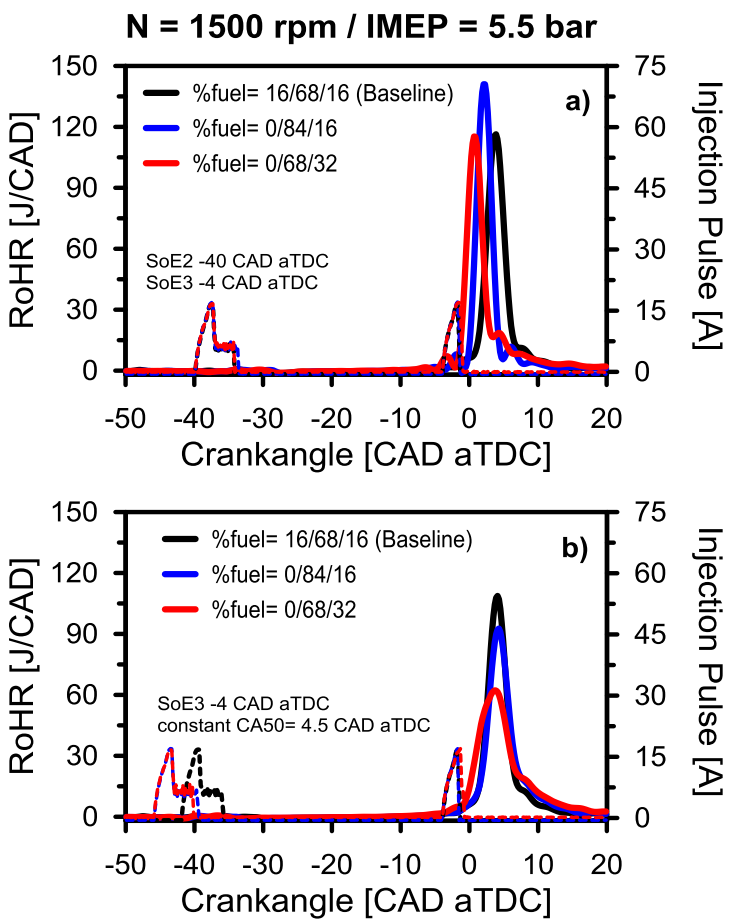

Figure 5: RoHR and injection pulse for baseline, \%fuel=0/84/16 and $\%$ fuel $=0 / 68 / 32$ cases at medium load point with 5.5 bar IMEP. Test are selected at a) constant SoE2 equal to -40 CAD aTDC and b) constant CA50 equal to $4.5 \mathrm{CAD}$ aTDC.

Page 8 of 16
To keep the CA50 phased at 4.5 CAD aTDC while removing the $1^{\text {st }}$ injection, it is necessary to advance SoE2 in 4 CAD, from - 42 CAD aTDC to $-46 \mathrm{CAD}$ aTDC, in order to match the mixture conditions (given by the local $\phi$ distribution) with the in-cylinder thermodynamic conditions (temperature and $\mathrm{YO}_{2}$ ). When $\%$ fuel $=0 / 84 / 16 \%$ and $\%$ fuel $=0 / 68 / 32$ cases are compared against the baseline at constant CA50, the longer combustion duration and lower maximum RoHR for \%fuel $=0 / 68 / 32$ indicate once again that a higher quantity of the fuel is burnt in the mixing-controlled stage, which is translated into higher smoke emissions and worse NOx/soot tradeoff, as confirmed by Figure 4.b. Even so, decreasing the premixed combustion phase allowed decreasing noise level down to $86 \mathrm{~dB}$, while $\mathrm{dP} / \mathrm{damax}$ was decreased to $5.3 \mathrm{bar} / \mathrm{CAD}$.

When the $3^{\text {rd }}$ injection is removed, \%fuel $=16 / 84 / 0$ and $\%$ fuel $=32 / 68 / 0$, the smoke level remained below the minimum detection limit in all the measured range of SoE2, as it is shown in Figure 4.b, since the diffusive combustion stage is completely avoided. However, following the expected trends, $\mathrm{NO}$ and also noise level are consequently increased, as a result of the higher fuel quantity burnt in premixed conditions.

The same trends are observed at the medium load case (10.4 bar IMEP) and therefore, in general terms, the experimental results confirms how both the fuel split between injections and SoE2 act as levers to control combustion rate and the shape of the RoHR, by affecting local equivalence ratio distribution and global mixture reactivity. Therefore, they have to be carefully optimized to attain the optimum CA50 and RoHR profile for achieving noise and pressure gradient requirements while meeting the low $\mathrm{NO}_{\mathrm{X}} /$ soot target.

Switching to $\mathrm{CO}$ and $\mathrm{HC}$ emissions, Figure 6 confirms how in the case of medium/high load conditions (5.5 and 10.4 bar IMEP), CO emissions increase from levels around $6 \mathrm{~g} / \mathrm{kWh}$ up to $7-8 \mathrm{~g} / \mathrm{kWh}$ for the points with earlier SoE2, and therefore, lower $\mathrm{NO}_{\mathrm{X}}$ emissions; while $\mathrm{HC}$ emissions increase from $2 \mathrm{~g} / \mathrm{kWh}$ in the case of late SoE2 up to $6-8 \mathrm{~g} / \mathrm{kWh}$ in the case of early SoE2. Additionally, increasing $\mathrm{P}_{\text {rail }}$ keeps $\mathrm{CO}$ almost unaffected, while $\mathrm{HC}$ emissions are clearly increased. In the case of \%fuel, introducing all the fuel mass in the two very early injections also brings an increment in $\mathrm{HC}$ emissions, while $\mathrm{CO}$ emissions are hardly affected. These two trends support the hypothesis of the spray/wall interaction as the source of HC emissions operating in PPC keeping early injection events.

At the lower load point (3.1 bar IMEP), a sharp increase in CO is observed when SoE2 is advanced; going from $8 \mathrm{~g} / \mathrm{kWh}$ to $16 \mathrm{~g} / \mathrm{kWh}$ in the case of \%fuel=0/40/60, and from $5 \mathrm{~g} / \mathrm{kWh}$ to $11 \mathrm{~g} / \mathrm{kWh}$ in the case of $\%$ fuel=0/60/40. Similar to medium/high load conditions, HC also increases when advancing SoE2, ranging from $2 \mathrm{~g} / \mathrm{kWh}$ to 9 $\mathrm{g} / \mathrm{kWh}$ for $\%$ fuel=0/40/60 and from $2 \mathrm{~g} / \mathrm{kWh}$ to $6 \mathrm{~g} / \mathrm{kWh}$ for $\%$ fuel $=0 / 60 / 40$. The higher $\mathrm{CO}$ and $\mathrm{HC}$ maximum levels observed for $\%$ fuel $=0 / 40 / 60$ are linked with the extended mixing-controlled stage which retarded combustion phasing, compared to $\%$ fuel $=0 / 60 / 40$. In general terms, the increase in $\mathrm{HC}$ and $\mathrm{CO}$ at this low load condition appears to be linked to the worsened oxidation processes, given by the increased spray/wall interactions and lower cylinder density and temperature.

Figure 7 shows combustion efficiency ( $\left.\eta_{\text {combustion}}\right)$ and indicated efficiency ( $\left.\eta_{\text {indicated }}\right)$ as function of SoE2 for the three operating conditions. In all operating conditions, results confirm how advancing SoE2 generates a trade-off between $\mathrm{NO}_{\mathrm{X}} /$ soot reduction and the deterioration of combustion efficiency. 

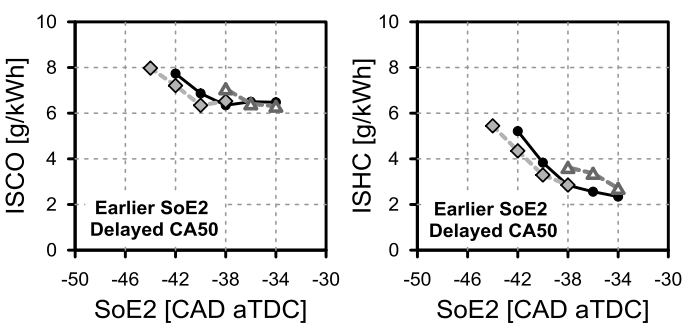

a) $N=1500 \mathrm{rpm}$
$\mathrm{IMEP}=10.4 \mathrm{bar}$

- $\mathrm{P}_{\text {rail }}=850 \mathrm{bar}$

(Baseline)

$\diamond P_{\text {rail }}=750$ bar

$\Delta P_{\text {rail }}=950$ bar
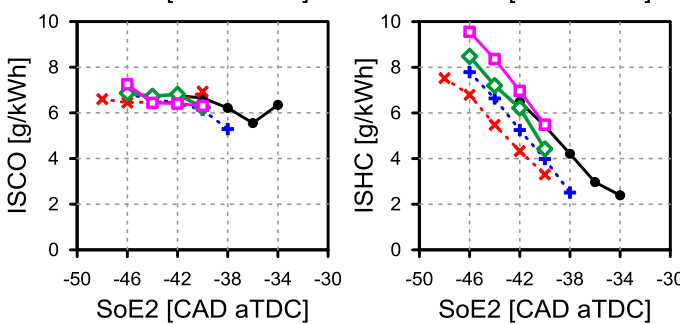

b) $\mathbf{N}=1500 \mathrm{rpm}$ IMEP $=5.5$ bar

\%fuel $=16 / 68 / 16$ (Baseline)

$+\%$ fuel $=0 / 84 / 16$

$x \%$ fuel $=0 / 68 / 32$

$\diamond \%$ fuel $=16 / 84 / 0$

$\%$ fuel $=32 / 68 / 0$
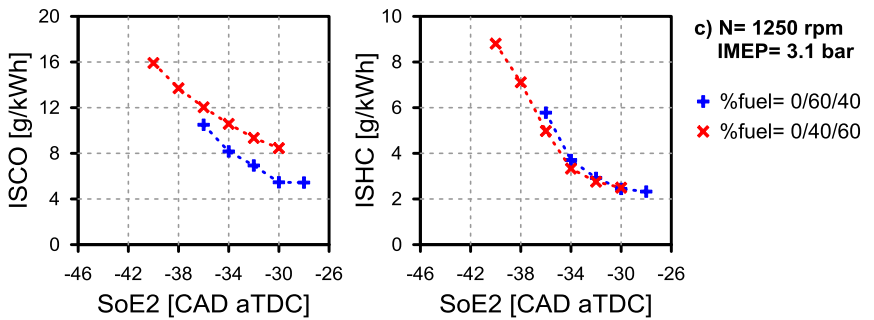

Figure 6: Effect of injection settings over the $\mathrm{CO}$ and $\mathrm{HC}$ emissions for a) $\mathrm{N}=1500 \mathrm{rpm} / \mathrm{IMEP}=10.4 \mathrm{bar}, \mathrm{b}) \mathrm{N}=1500 \mathrm{rpm} / \mathrm{IMEP}=5.5 \mathrm{bar}$ and c) $\mathrm{N}=1250 \mathrm{rpm} / \mathrm{IMEP}=3.1 \mathrm{bar}$

Additionally, the effects of $\mathrm{P}_{\text {rail }}$ and fuel split between injections corresponds to those observed in Figure 6, and it is evident that the differences in $\eta_{\text {combustion observed in Figure } 7 \text { for different }} P_{\text {rail }}$ and \%fuel are mostly caused by $\mathrm{HC}$ emissions, since $\mathrm{CO}$ emissions are not significantly affected.

At 10.4 bar IMEP $\eta_{\text {indicated }}$ ranges between $47 \%$ and $48 \%$ and remains approximately constant when advancing SoE2, which corresponds to values of ISFC between 181 to $176 \mathrm{~g} / \mathrm{kWh}$. This efficiency level is promising since it represents a $10 \%$ improvement compared to that attained after a detailed optimization operating with the CDC concept.

At 5.5 bar IMEP, $\eta_{\text {indicated }}$ ranges between $41 \%$ and $43 \%$ as shown in Figure 7.b, showing a slight improvement when advancing SoE2, which corresponds with a reduction in ISFC from 204 to $196 \mathrm{~g} / \mathrm{kWh}$, even when combustion efficiency is decreased from $98 \%$ to $96-95 \%$. At 3.1 bar IMEP, $\eta_{\text {indicated }}$ becomes more sensitive to the changes in the combustion process, ranging between $39-38 \%$ with ISFC of 216 to $221 \mathrm{~g} / \mathrm{kWh}$ for \%fuel $=0 / 60 / 40$ and $38-37 \%$ with ISFC of 221 to $226 \mathrm{~g} / \mathrm{kWh}$ for $\%$ fuel=0/40/60.

Nevertheless, even when the indicated efficiency levels observed in the medium-to-low load range operating with the PPC concept using a multiple injection strategy are lower than those observed operating with the CDC concept, as it will be discussed in the next section. However, they are still considered as promising, since they are kept within the range of values reported in the literature on light-duty 4stroke engines running with the PPC concept at low load conditions with lower octane gasoline fuels [29]. Furthermore, Sellnau et al. reported important benefits in efficiency and emissions levels using dedicated engine hardware (piston and injector nozzle) welloptimized for PPC operation compared to using conventional hardware optimized for CDC $[39,40]$.

Page 9 of 16
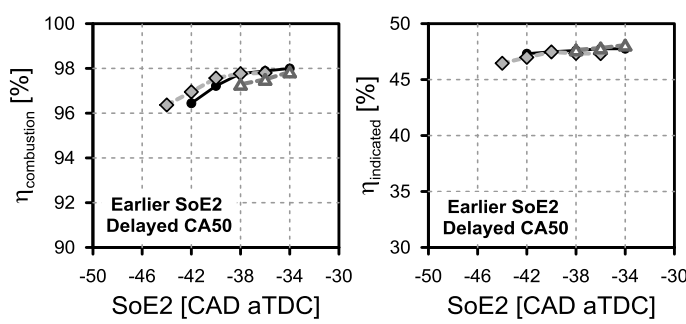

a) $N=1500 \mathrm{rpm}$
$\mathrm{IMEP}=10.4$ ba

$\mathrm{P}_{\text {rail }}=850 \mathrm{bar}$

(Baseline)

$\diamond \mathrm{P}_{\text {rail }}=750$ bar

$\Delta P_{\text {rail }}=950$ bar
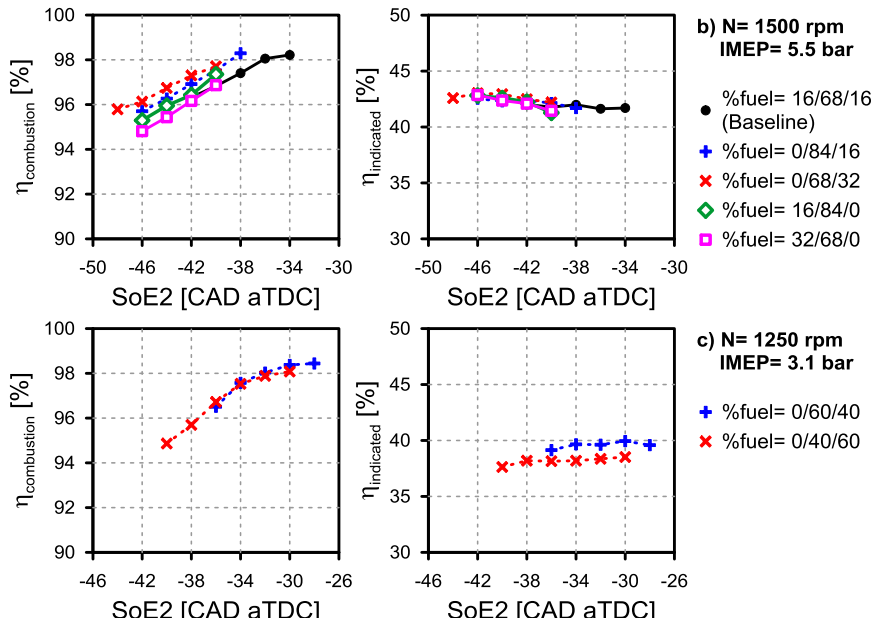

Figure 7: Effect of injection settings over the combustion and indicated efficiencies for a) N=1500 rpm / IMEP=10.4 bar, b) N=1500 rpm / IMEP=5.5 bar and c) $\mathrm{N}=1250 \mathrm{rpm} / \mathrm{IMEP}=3.1$ bar.

As a final remark, previous research performed at 10.4 bar IMEP showed how retarding the timing of the late injection (SoE3) can also be used to control noise by softening and slowing combustion rate once the combustion starts, but with a moderate effect compared to SoE2 [44]. However, the increase in smoke emissions due to the transition towards mixing-controlled combustion is unavoidable. At medium/high load conditions, the intrinsically higher local temperatures and enhanced trend towards knocking-like combustion increase the complexity for further decreasing noise and $\mathrm{dP} / \mathrm{da} \mathrm{amax}_{\max }$ levels without worsening soot or combustion stability when using a simple parametric optimization of the injection timings. Therefore, a Design of Experiment (DoE) methodology will be implemented in the future, in order to analyze simultaneously the impact of the injection and the air management parameters, to properly determine the optimum engine settings for PPC. Therefore, there is still great room for improvement by performing a detailed optimization of the engine hardware combined with an in-depth DoE optimization of the air management settings and the injection strategy.

\section{Comparative analysis between gasoline PPC and CDC concepts}

An optimum point for gasoline PPC operation in terms of $\mathrm{NO}_{\mathrm{X}} / \mathrm{soot}$ and noise levels is selected at each operating condition, in order to be compared against well-optimized points obtained operating in CDC after performing a DoE optimization following the methodology described in previous publications [11,44]. The optimum points measured in CDC were selected to improve Euro 5 emissions levels measured on the equivalent 4-stroke engine in terms of unitary displacement and geometry, while also providing the best compromise with indicated fuel consumption. . Despite the comparison is not performed keeping iso-NOx conditions, which could be an attractive alternative, the key benefits/drawbacks of each combustion concept are clearly observed. 
a) $\mathbf{N}=1500 \mathrm{rpm} /$ IMEP = $10.4 \mathrm{bar}$

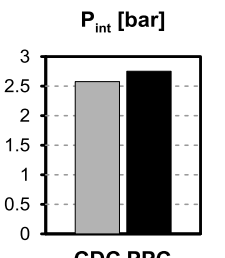

CDC PPC

ISNO $[$ [g/kWh]

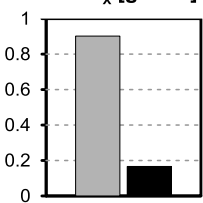

CDC PPC

Noise [dB]

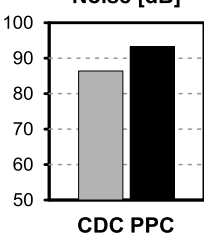

CDC PPC

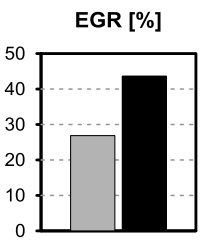

CDC PPC

Smoke [FSN]

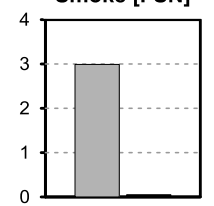

CDC PPC

ISFC [g/kWh]

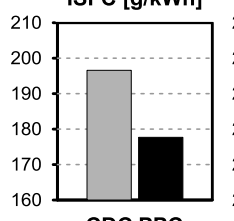

CDC PPC

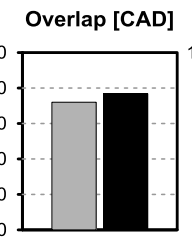

CDC PPC

ISCO $[\mathrm{g} / \mathrm{kWh}]$

CDC PPC

ISFC $_{\text {corr }}[\mathrm{g} / \mathrm{kWh}]$

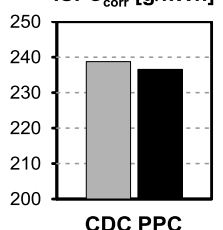

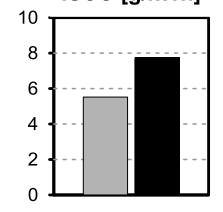

$P$ rail [bar]

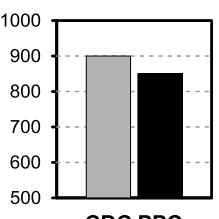

CDC PPC

ISHC [g/kWh]

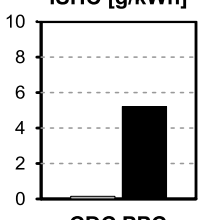

CDC PPC

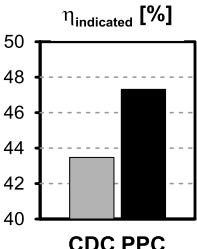

Figure 8: Comparison between CDC and gasoline PPC optimum points for $\mathrm{N}=1500 \mathrm{rpm} / \mathrm{IMEP}=10.4$ bar.

Figure 8 summarizes the main engine settings and most important pollutant emissions, noise and fuel consumption levels for CDC and PPC optimum points; measured at the higher load condition, with 10.4 bar IMEP and $1500 \mathrm{rpm}$. To assure the cylinder conditions required for PPC operation at the higher load point (10.4 bar IMEP) it was necessary to increase $\mathrm{P}_{\text {int }}, \Delta \mathrm{P}$ and overlap to increase the fresh air trapped mass, allowing the use of a higher EGR rate compared to CDC. Moreover, the triple injection strategy allowed reducing $P_{\text {rail }}$ compared to CDC without punishing soot emissions, which is interesting for reducing the compression power from the fuel pump.

Operating with the gasoline PPC concept allowed decreasing simultaneously $\mathrm{NO}_{\mathrm{X}}$ and soot emissions down to $0.17 \mathrm{~g} / \mathrm{kWh}$ and $0.05 \mathrm{FSN}$, compared to $0.9 \mathrm{~g} / \mathrm{kWh}$ and $2.99 \mathrm{FSN}$ obtained in the optimum point for CDC. CO and HC emissions are increased to 7.73 $\mathrm{g} / \mathrm{kWh}$ and $5.21 \mathrm{~g} / \mathrm{kWh}$ which corresponds to $\eta_{\text {combustion }}$ around $96.5 \%$, compared to $5.52 \mathrm{~g} / \mathrm{kWh}, 0.15 \mathrm{~g} / \mathrm{kWh}$ and $99 \%$ for CDC, due to the early timing of the $1^{\text {st }}$ and $2^{\text {nd }}$ injection combined with poor injector nozzle matching. Moreover, combustion noise is noticeably higher when operating in PPC at the medium-to-high load range compared to CDC, increasing from $86.4 \mathrm{~dB}$ to $93.3 \mathrm{~dB}$, due to the fast and short combustion process given by the enhanced tendency towards knocking-like combustion.

PPC operation allowed increasing $\eta_{\text {indicated }}$ from $43 \%$ to $47 \%$, which corresponds to the highest value observed so far in the engine at this load condition. The increased indicated efficiency is reflected in a reduction in ISFC from $197 \mathrm{~g} / \mathrm{kWh}$ to $178 \mathrm{~g} / \mathrm{kWh}$ when operating in PPC, as shown in Figure 8. However, if the compression work demanded by the supercharging system (SC/TC) is taken into account to correct the ISFC values, the more demanding air management conditions required to achieve higher $\mathrm{P}_{\text {int }} / \mathrm{EGR}$ combination could mask the benefits of PPC operation in terms of indicated efficiency. The estimation of ISFC corr $_{\text {is }}$ useful for evaluating qualitatively the increase in BSFC expected at the two-cylinder engine with fully assembled air charging system, and also to discard air management conditions which are not feasible due to extremely high pressure ratios or air flow rates. In this case, Figure 8 confirms the lower gain Page 10 of 16 in terms of ISFC $_{\text {corr }}$ when the compression work demanded by the air charging devices is considered, going from $239 \mathrm{~g} / \mathrm{kWh}$ while operating in CDC to $236 \mathrm{~g} / \mathrm{kWh}$ when operating with gasoline PPC.

At 5.5 and 3.1 bar IMEP, a combination of slightly higher $\mathrm{P}_{\text {int }}$ with lower $\Delta \mathrm{P}$ and earlier timing of the exhaust valve to reduce overlap compared to CDC is used to assure the required level of IGR to keep a reliable ignition and a high combustion stability during PPC operation. The most important engine settings together with the measured emission and ISFC levels are shown in Figure 9 and Figure 10 respectively.

b) $\mathbf{N}=1500 \mathrm{rpm} /$ IMEP $=\mathbf{5 . 5}$ bar
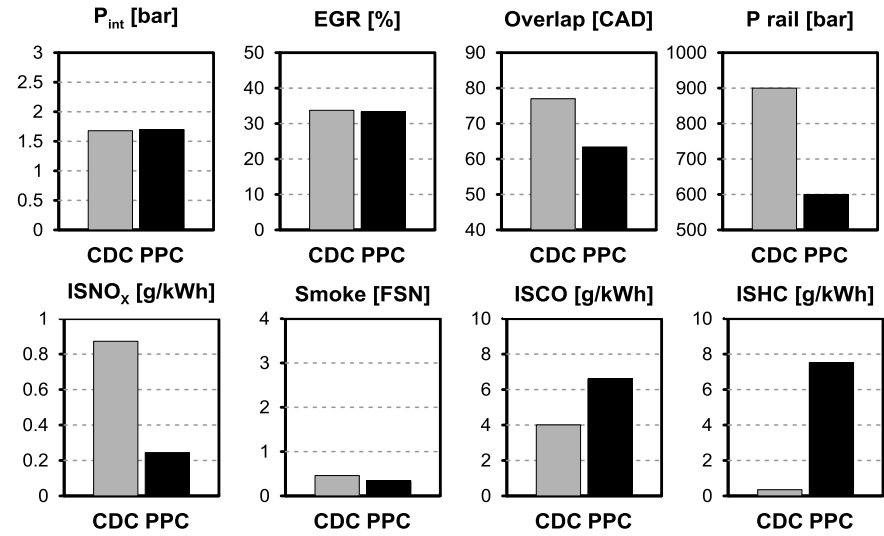

ISHC $[\mathbf{g} / \mathbf{k W h}]$

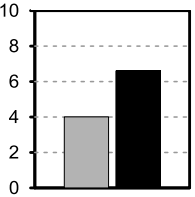

CDC PPC

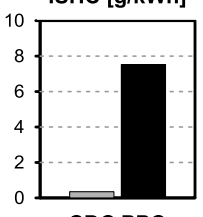

Noise $[\mathrm{dB}]$
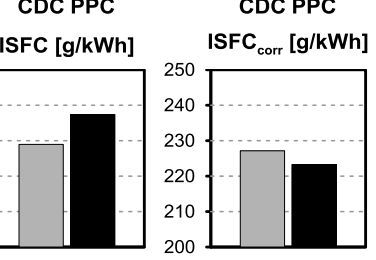

CDC PPC
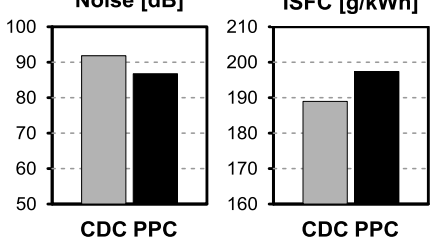

CDC PPP

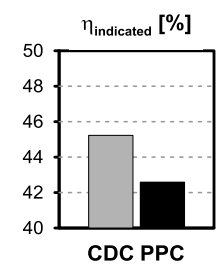
$\mathrm{N}=1500 \mathrm{rpm} / \mathrm{IMEP}=5.5 \mathrm{bar}$.

c) $\mathbf{N}=1250 \mathrm{rpm} /$ IMEP = $3.1 \mathrm{bar}$
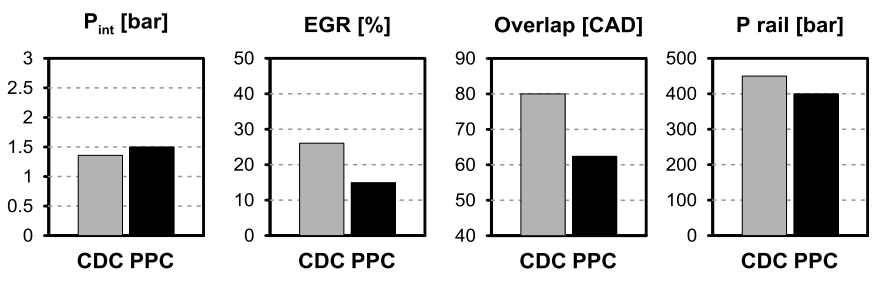

ISNO $_{x}[g / k W h]$
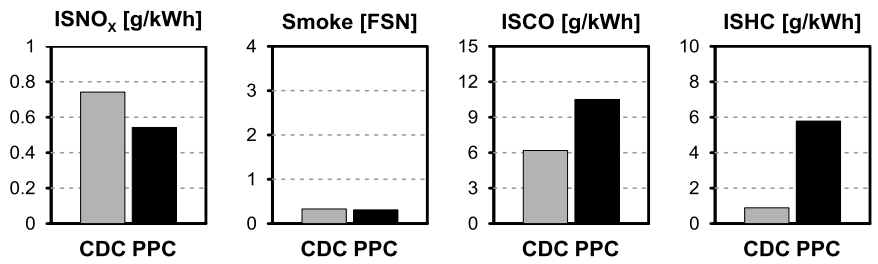

ISFC [g/kWh]
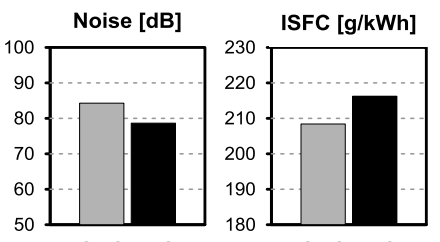

ISFC

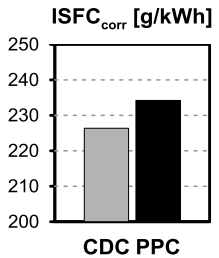

CDC PPC

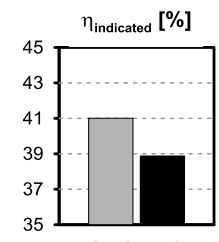

Figure 10: Comparison between CDC and gasoline PPC optimum points for $\mathrm{N}=1250 \mathrm{rpm} / \mathrm{IMEP}=3.1 \mathrm{bar}$. 
At the medium-to-low load range, lower $\mathrm{NO}$ /smoke compared to $\mathrm{CDC}$ is attained at the expense of increased $\mathrm{CO}$ and $\mathrm{HC}$, while $\eta_{\text {indicated }}$ is decreased operating in PPC, possibly due to the increased heat transfer losses caused by the high temperature at IVC required to ignite the gasoline at these loads and the slightly lower combustion efficiency, but also due to the earlier EVO which decreases the effective expansion ratio compared to the optimum settings found in CDC. At 5.5 bar IMEP case, $\eta_{\text {indicated }}$ drops from $45 \%$ to $43 \%$ following an increase in ISFC from $189 \mathrm{~g} / \mathrm{kWh}$ to $197 \mathrm{~g} / \mathrm{kWh}$, while ISFC $_{\text {corr }}$ still decreases from $227 \mathrm{~g} / \mathrm{kWh}$ to $224 \mathrm{~g} / \mathrm{kWh}$ due to slightly lower delivered flow given by the air management settings, specially overlap and $\Delta$ P. At 3.1 bar IMEP case, $\eta_{\text {indicated }}$ decreases from $41 \%$ to $39 \%$, which corresponds to an increase in ISFC from 208 to 216 $\mathrm{g} / \mathrm{kWh}$, bringing in this case a consequent increase in $\mathrm{ISFC}_{\text {corr }}$ from 226 to $234 \mathrm{~g} / \mathrm{kWh}$. Finally, for both 5.5 and 3.1 bar IMEP cases it is possible to decrease noise level below the measured optimum points for CDC by delaying CA50 and controlling the shape of the RoHR with the fuel split between the injections.

\section{Analysis of local conditions operating with the gasoline PPC concept and triple injection strategy at medium load (5.5 bar IMEP)}

The analysis of local conditions is performed at the medium load point with 5.5 bar IMEP and $1500 \mathrm{rpm}$ for the baseline test, keeping the triple injection strategy with SoE2 equal to -40 CAD aTDC. The quality of the model was evaluated by comparing its combustion and emissions results with those measured experimentally in the engine. Table 4 shows the comparison in terms of exhaust emissions between the CFD and experimental results; while Figure 11 shows the CFD and experimental cylinder pressure and RoHR profiles.

In general terms, the results showed reasonably good agreement between the experiments and the simulations in terms of cylinder pressure and RoHR. However, some differences in the emissions levels were detected. For instance, $\mathrm{CO}, \mathrm{HC}$ and soot emissions are over-predicted in the calculation, while the model predicts lower $\mathrm{NO}_{\mathrm{X}}$ level compared to the measurement.

Table 4: Exhaust emissions comparison between CFD and experimental results at baseline for $\mathrm{N}=1500 \mathrm{rpm} / \mathrm{IMEP}=5.5 \mathrm{bar}$.

\begin{tabular}{|l|cccc|}
\hline \multicolumn{5}{|c|}{ b) } \\
\hline $\begin{array}{c}\text { Baseline with } \\
\text { SoE2 } 2=-40 \text { CAD } a T D C\end{array}$ & $\begin{array}{c}I S C O \\
{[g / k W h]}\end{array}$ & $\begin{array}{c}\text { Soot } \\
{[g / k W h]}\end{array}$ & $\begin{array}{c}I S H C \\
{[g / k W h]}\end{array}$ & $\begin{array}{c}I S N O_{X} \\
{[g / k W h]}\end{array}$ \\
\hline CFD & 11.02 & 0.0042 & 8.83 & 0.18 \\
Experimental & 6.18 & 0.0038 & 5.14 & 0.33 \\
\hline
\end{tabular}

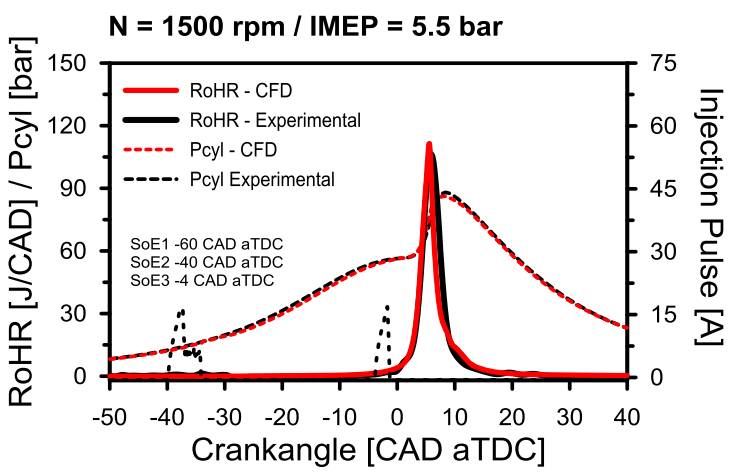

Figure 11: CFD and experimental RoHR and cylinder pressure profiles at baseline for N=1500 rpm / IMEP=5.5 bar, with SoE2 -40 CAD aTDC.

Page 11 of 16
Despite the slight differences in the absolute levels in terms of exhaust emissions, the performance of the model can be considered as suitable for being used to evaluate qualitatively local cylinder conditions and support the experimental results obtained in the single cylinder engine.

Figure 12 shows the local equivalence ratio of the gas mixture in a cross-section throughout the cylinder centerline at different crankangle positions. The intake valves are located in the left side of the combustion chamber, and the mask in the cylinder head limits the flow of fresh air towards the exhaust valves during the scavenging process, and creates a tumble structure of the flow instead of the conventional swirl motion used in CI engines. The first injection is timed relatively early with SoE1 -60 CAD aTDC when the piston is well below the TDC. The spray is targeted above the piston bowl and, since temperature and density are still low at this CAD, the vaporization of the liquid fuel and spray mixing is less efficient; therefore, the total mass is injected is limited to $16 \%$, to keep a short pulse and limit the fuel penetration into the cold squish region. In general, the majority of the injected fuel is mixed in the chamber to an overall lean equivalence ratio. However, by the time when the $2^{\text {nd }}$ injection starts, there are still some zones with $\phi$ ranging between 0.6-0.8 near the cylinder wall in the intake side, as seen in Figure 12, for $-35 \mathrm{CAD}$ aTDC.

During the $2^{\text {nd }}$ injection, the spray penetrates the combustion chamber, targeting the top of the piston bowl so the spray is split by the bowl lip, deflecting part of the fuel inside the bowl but also pushing fuel into the cold squish region, as shown at -27 CAD aTDC. The fuel trapped in the squish region takes more time to properly mix with air so it remains in rich $\phi$ by the time when the $3^{\text {rd }}$ injection starts (around TDC), while the remaining fuel inside the bowl reaches lean $\phi$ faster. For this reason, advancing SoE2 extends the mixing time available for premixing the charge before the $\mathrm{SoC}$, but it also increases the fuel/wall interaction between the spray and the piston top land regions, so a higher portion of the fuel remains in rich $\phi$ at the squish region by the time of SoE3. Moreover, as confirmed by Figure 12 at -1 CAD aTDC, the staggered shape of the combustion chamber added to the tumble motion of air creates a non-symmetric $\phi$ distribution between the intake and exhaust sides, so the mixture remains at locally higher $\phi$ in the exhaust (right) side.

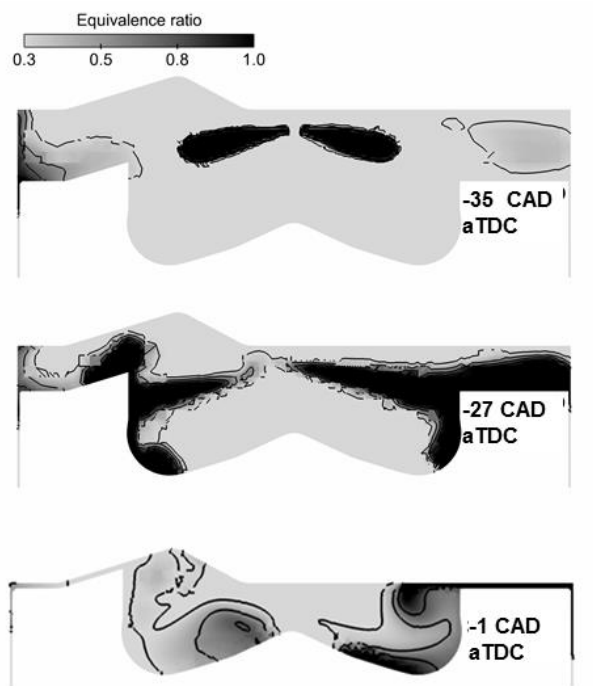

Figure 12: Equivalence ratio distribution at baseline for $\mathrm{N}=1500 \mathrm{rpm} /$ IMEP=5.5 bar, with SoE2 -40 CAD aTDC. 
To better illustrate the effect of SoE2 over local $\phi$ distribution, Figure 13 shows a detailed description of the fuel mass distributed along different $\phi$ zones, for three calculated cases with SoE2 equal to -44 (early), -40 (reference) and -36 (late) CAD aTDC, evaluated at the instant right before the start of combustion. If the early injection timing case with SoE2 -44 is compared against the reference and late SoE2 -36, there is lower fuel mass located under the 0.6-0.9 $\phi$ range (in black), while the mass under both rich (in red) and lean (in blue) $\phi$ are consequently increased. As a consequence, the mixture reactivity by the time of $\mathrm{SoC}$ is consequently decreased, explaining the enhanced misfire trend when advancing SoE2. This observed effect is in agreement with the CFD results obtained at the 10.4 bar IMEP point previously reported by the authors [44].

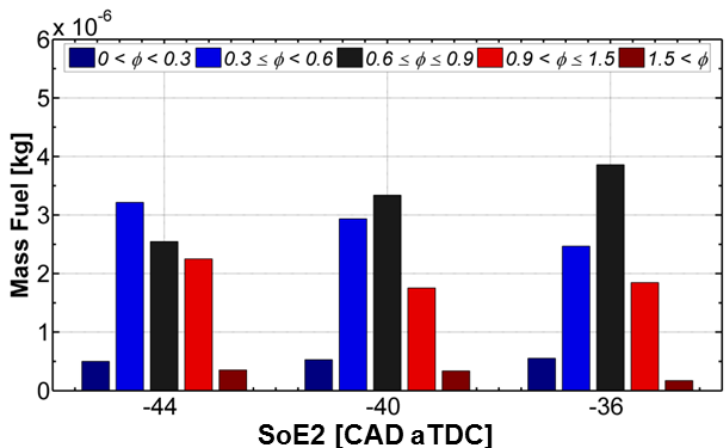

Figure 13: Fuel mass distribution as function of $\phi$ evaluated right before the SoC, at baseline test $\mathrm{N}=1500 \mathrm{rpm} / \mathrm{IMEP}=5.5$ bar, with SoE2 equal to -44 (left), -40 (middle) and -36 (right) CAD aTD

Figure 14 shows the temperature, $\mathrm{CO}$ and soot spatial distribution in the selected cross-section, for different representative instants along the combustion process (CA10, CA50 and CA90) and after the end of combustion during the expansion stroke (40 CAD aTDC). The equivalence ratio is represented in contour lines in greyscale, while the other variables are displayed in color.
The temperature required for gasoline auto-ignition (around $950 \mathrm{~K}$ ) is reached around TDC, and consequently the charge will be ignited in the zones with $\phi$ within the reactive range $(0.7-1.1)$ and with the highest local temperature. Since most of the fuel has been injected in the early injections, enough mixing time is provided to premix the fuel-air charge, until reaching highly reactive $\phi$ distribution before the SoC. The late $3^{\text {rd }}$ injection occurs simultaneously while combustion is being initiated in the upper area of the bowl at the exhaust side (right side of combustion chamber); close to a reactive zone with $\phi$ equal to 1 , which results from the fuel injected primarily in the $2^{\text {nd }}$ injection, as observed in Figure 14 by the time of CA10.

Once combustion has been initiated, the fuel coming from the $3^{\text {rd }}$ injection will burn in mixing-controlled conditions, as confirmed by the local temperature distribution shown at CA50 (7 CAD aTDC). However, combustion progresses mostly after the end of injection since the $3^{\text {rd }}$ injection only introduces the $16 \%$ of the total fuel. The combustion duration is considerably shorter compared to CDC, with CA90 around 13 CAD. Finally, a region with relatively lower temperatures $(1200 \mathrm{~K}$ to $1600 \mathrm{~K})$ appears near the core of the combustion chamber close to the cylinder head and in the squish region of the cylinder on the intake side (left), where mainly leaner mixtures with $\phi$ between 0.6-0.4 are found, which will difficult complete combustion and later oxidation of the of the fuel.

Two main regions where $\mathrm{CO}$ forms are clearly identified from Figure 14. The first region corresponds to the rich $\phi$ areas (between 1 and 2.5) located in the inner side of the spray structure, and also in the squish region on the exhaust side; while the second region appears at areas with lean $\phi$ (between 0.6 and 0.4) distributed along the core of the combustion chamber close to the cylinder head and in the squish region on the intake side. The $\mathrm{CO}$ formed in relatively high $\phi$ conditions will likely be oxidized along the combustion process; because combustion temperatures are high enough to assure proper CO-CO2 conversion. However, the slower reacting, over-lean mixtures located in the squish region and in the central part of the cylinder, with temperatures lower than $1500 \mathrm{~K}$, will not be properly oxidized; thus, becoming the main source of $\mathrm{CO}$ and $\mathrm{HC}$ emissions, as reported by Musculus et al [60].
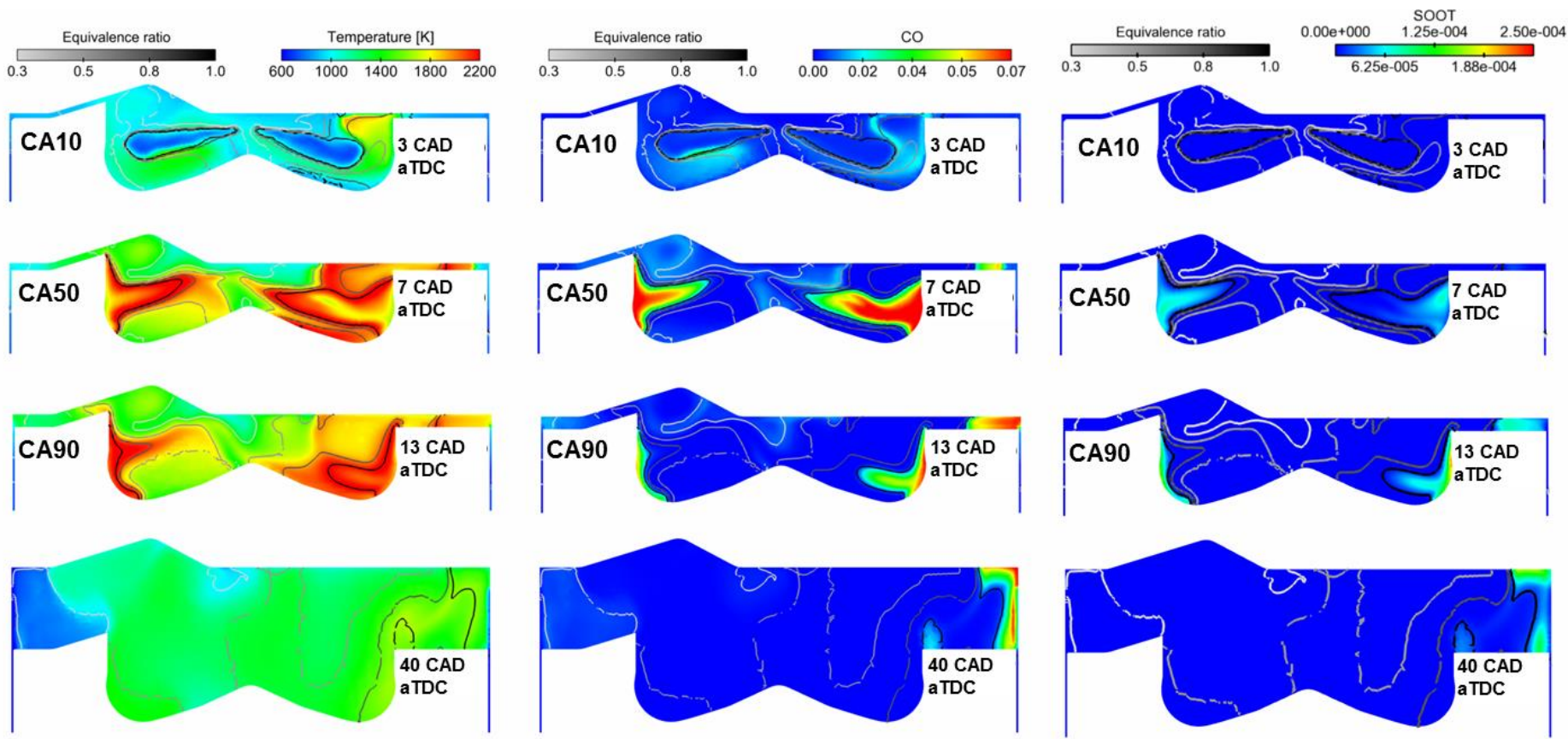

Figure 14: Temperature (left), CO (middle) and soot (right) spatial distribution at baseline for N=1500 rpm / IMEP=5.5 bar, with SoE2 -40 CAD aTDC.

Page 12 of 16 

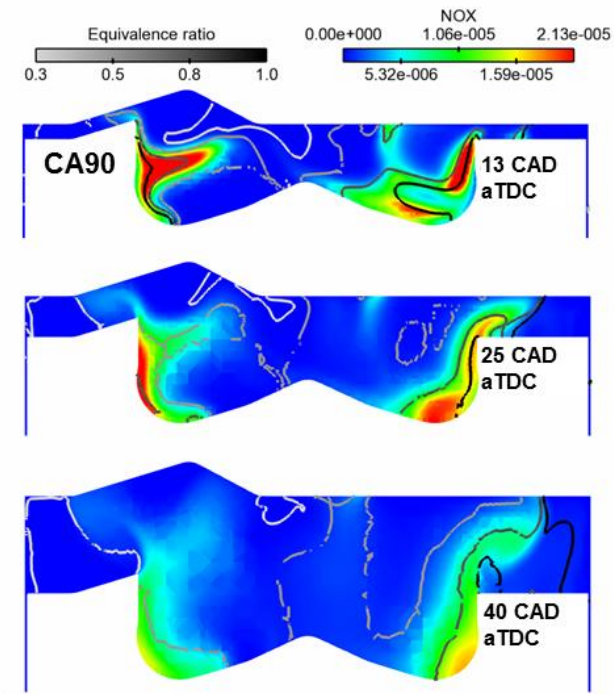

Figure 15: $\mathrm{NO}_{\mathrm{X}}$ spatial distribution at baseline for $\mathrm{N}=1500 \mathrm{rpm} / \mathrm{IMEP}=5.5$ bar, with SoE2 -40 CAD aTDC.

Figure 14 also confirms how the soot formation is concentrated primarily in the zones with $\phi$ over 1 and 2 in the inner side of the sprays, as it was expected, close to the bowl walls where combustion develops and temperatures are the highest. For the modeled case with SoE2 -40 CAD aTDC, the soot level is very low, mainly because the fuel injected in the $3^{\text {rd }}$ injection is mixed enough before the SoC, so the extremely high $\phi$ regions are avoided during combustion.

Nevertheless, as previously discussed in Figure 4, the final soot level will result from the balance between formation and oxidation processes, so it will be affected by the timing and fuel mass injected in the $2^{\text {nd }}$ and specially in the $3^{\text {rd }}$ injection, by the mixing rate and also by the conditions at the final stages of combustion.

The experimental results also showed how advancing SoE2 brought a sharp increment in $\mathrm{HC}$ emissions. In this frame, investigating in detail the trend followed by the liquid film attached to the combustion chamber walls (especially the liner wall) as SoE2 advances from -36 to -44 CAD aTDC; the CFD simulations reveals that the liquid film is noticeably increased by advancing SoE2 earlier than -40 CAD aTDC, which also supports the hypothesis of the spray/wall interaction as the main source of $\mathrm{HC}$.

Finally, it is widely known that at PPC operation, the reduction in $\mathrm{NO}_{\mathrm{X}}$ emissions is mainly attained by decreasing maximum combustion temperatures through the use of high EGR rates, instead of diluting the air/fuel mixture to homogenously lean $\phi$, like in the case of fully-premixed or HCCI combustion. Figure 15 shows how $\mathrm{NO}_{\mathrm{X}}$ is observed during the final stages of combustion, after the CA90, mainly in regions with $\phi$ between 0.5 and 1 , where a combination of high temperatures and oxygen availability favors the $\mathrm{NO}$ formation. However, in the modeled case with SoE2 at -40 CAD aTDC the $\mathrm{NO}_{\mathrm{x}}$ level is already quite low; firstly, because the low oxygen concentration allows keeping combustion temperatures under $2300 \mathrm{~K}$, therefore slowing NOx formation; and secondly, because of the late CA50 and slower combustion rate given by the lower mixture reactivity obtained with early SoE2.

In general, the detailed analysis of local conditions is interesting to aid in the understanding of the basic physics involved in the particular combustion process, observed when operating in PPC with multiple injection strategies. From the CFD results, it is evident how the development of the combustion process and pollutant emissions is

Page 13 of 16 controlled by local conditions, which are not only sensitive to the air management and injection strategy, but also to the combustion chamber geometry. As a conclusion, there is a clear room for improving the performances of the PPC concept, in terms of controlling the maximum combustion rate to decrease pressure gradient and noise level, together with increasing combustion efficiency to decrease $\mathrm{CO}$ and $\mathrm{HC}$ emissions, while impacting also positively in ISFC as a result of the increment in the energy released by the fuel. Future research will focus in optimizing the local $\phi$ distribution in the combustion chamber, not only by further DoE optimization of the engine settings, but also by matching the bowl shape and fuel spray to reduce propensity for fuel wall wetting.

\section{Summary and Conclusions}

An experimental investigation was performed in a light-duty, singlecylinder 2-stroke HSDI CI engine using RON 95 gasoline fuel, operating with the PPC concept using multiple injection strategies, for three different engine operating conditions. The final comparison between the results obtained operating with gasoline PPC against well-optimized CDC, provides an overview of the main benefits and drawbacks of the PPC concept at low and medium load conditions. The key points can be summarized as follow:

In the three load conditions, operating with the gasoline PPC concept allows decreasing simultaneously $\mathrm{NOx}$ and soot emissions compared to a well-optimized CDC operation points. The reduction in $\mathrm{NO}_{\mathrm{X}}$ and soot emissions is more evident at the medium-to-high load range, because the premixed stage of combustion helps reducing the mixingcontrolled or spray driven combustion compared to CDC.

Soot emissions are greatly determined by the available mixing time for the late injection close to TDC. Therefore, the timing and duration of this injection, as well as the injection pressure and onset of combustion will affect final soot level. The use of a multiple injection strategy combined with the PPC concept allowed decreasing injection pressure compared to CDC without penalties in soot emissions. Additionally, NOx emissions are reduced by the use of large amounts of EGR with much lower penalties in terms of soot compared to CDC.

As a drawback, $\mathrm{CO}$ and $\mathrm{HC}$ emissions increase compared to CDC, due to increased spray/wall interactions from the early injections added to worsened oxidation processes.

At 10.4 bar IMEP, combustion noise is noticeably higher operating in PPC compared to CDC, due to the fast and short combustion process and enhanced knock trend given by the inherently higher temperatures. Noise is reduced while decreasing $\mathrm{NO}_{\mathrm{X}}$ and soot by advancing SoE2 to delay CA50. It could be decreased furthermore to some extent, by delaying SoE3 or increasing the fuel split in the $3^{\text {rd }}$ injection, but at the expense of an increase in soot emissions.

At 5.5 and 3.1 bar IMEP, it is possible to decrease noise below the levels obtained for CDC, by delaying CA50 with early SoE2, and by controlling the shape of the RoHR with the fuel split between injections.

The benefits of the PPC concept in terms of indicated efficiency compared to CDC were mostly observed in the medium-to-high load range, where a faster combustion process with lower mean gas temperatures allows decreasing heat losses during the cycle. 
At the medium-to-low load range, the indicated efficiency decreases while operating in PPC for both 5.5 bar and 3.1 bar IMEP optimum points, possibly due to increased heat transfer losses coming from the use of higher IGR rates combined with lower combustion efficiencies. But also by the earlier EVO timing, which is advanced compared to CDC to further increase the temperature at IVC, and finally decreases the effective expansion ratio possibly causing an additional increase in ISFC.

It is of great interest to estimate the power demanded by the air loop devices (turbocharger and supercharger) to achieve the required $\mathrm{EGR} /$ deff combination, and accordingly correct the ISFC to qualitatively predict the penalty expected in the multi-cylinder engine when operating with the PPC concept. The benefits obtained in ISFC at high load operation could be masked if high power is required by the supercharger to achieve the required intake conditions.

Finally, a new design of the piston and injector nozzle geometry to improve its compatibility with the gasoline PPC concept is expected to allow even further improvements. A detailed optimization work using a Design of Experiments (DoE) methodology can be useful not only to understand coupled effects that influence the combustion and emissions formation, but also to find the best injection pattern that can simultaneously fulfill the future requirements and restrictions in terms of emissions and noise when operating in PPC.

\section{References}

1. Dec, J.E., "A Conceptual Model of Di Diesel Combustion Based on Laser-Sheet Imaging," SAE Technical Paper 970873, 1997, doi: $10.4271 / 970873$.

$2 . \quad$ Dec, J.E., and Canaan, R.E., "Plif Imaging of No Formation in a Di Diesel Engine," SAE Technical Paper 980147, 1998, doi: $10.4271 / 980147$.

3. Kitamura, Y., Mohammadi, A., Ishiyama, T., and Shioji, M., "Fundamental Investigation of Nox Formation in Diesel Combustion under Supercharged and Egr Conditions," SAE Technical Paper 2005-01-0364, 2005, doi: 10.4271/2005-01-0364. 4. Flynn, P.F., Durrett, R.P., Hunter, G.L., and Zur Loye, A.O., "Diesel Combustion: An Integrated View Combining Laser Diagnostics, Chemical Kinetics, and Empirical Validation," SAE Technical Paper 1999-01-0509, 1999, doi.

5. $\quad \mathrm{Xu}, \mathrm{Y}$., and Lee, C.-f.F., "Investigation of Soot Formation in Diesel Combustion Using Forward Illumination Light Extinction (File) Technique," SAE Technical Paper 2004-01-1411, 2004, doi: 10.4271/2004-01-1411.

$6 . \quad$ Johnson, T.V., "Vehicular Emissions in Review." SAE Int. J. Engines 5(2):216-234, 2012, doi: 10.4271/2012-01-0368.

$7 . \quad$ Berggren, C., and Magnusson, T., "Reducing Automotive Emissions - the Potentials of Combustion Engine Technologies and the Power of Policy." Energy Policy 41(0):636-643, 2012, doi: http://dx.doi.org/10.1016/j.enpol.2011.11.025.

8. $\quad$ Squaiella, L.L.F., Martins, C.A., and Lacava, P.T., "Strategies for Emission Control in Diesel Engine to Meet Euro Vi." Fuel 104(0):183-193, 2013, doi: http://dx.doi.org/10.1016/j.fuel.2012.07.027.

$9 . \quad$ Yao, M., Zheng, Z., and Liu, H., "Progress and Recent Trends in Homogeneous Charge Compression Ignition (Hcci) Engines." Prog. Energy Combust. Sci. 35(5):398-437, 2009, doi: http://dx.doi.org/10.1016/j.pecs.2009.05.001.

10. Tribotte, P., Ravet, F., Dugue, V., Obernesser, P., et al., "Two Strokes Diesel Engine - Promising Solution to Reduce Co2 Emissions." Procedia - Social and Behavioral Sciences 48):22952314, 2012, doi: 10.1016/j.sbspro.2012.06.1202.

Page 14 of 16
11. Benajes, J., Novella, R., De Lima, D., Tribotte, P., et al., "Analysis of the Combustion Process, Pollutant Emissions and Efficiency of an Innovative 2-Stroke Hsdi Engine Designed for Automotive Applications." Appl. Therm. Eng. 58):181-193, 2013, doi: 10.1016/j.applthermaleng.2013.03.050.

12. Benajes, J., Novella, R., De Lima, D., Dugue, V., et al., "The Potential of Highly Premixed Combustion for Pollutant Control in an Automotive Two-Stroke Hsdi Diesel Engine," SAE Technical Paper 2012-01-1104, 2012, doi: 10.4271/2012-01-1104.

13. Benajes, J., Novella, R., De Lima, D., Quechon, N., et al., "Implementation of the Early Injection Highly Premixed Combustion Concept in a Two-Stroke Hsdi Engine," presented at SIA Diesel Powertrain Congress 2012, France, June 5-6, 2012.

14. Takeda, Y., Keiichi, N., and Keiichi, N., "Emission Characteristics of Premixed Lean Diesel Combustion with Extremely Early Staged Fuel Injection," SAE Technical Paper 961163, 1996, doi.

15. Ryan, T.W., and Callahan, T.J., "Homogeneous Charge Compression Ignition of Diesel Fuel," SAE Technical Paper 961160, 1996, doi: $10.4271 / 961160$.

16. Walter, B., and Gatellier, B., "Development of the High Power Naditm Concept Using Dual Mode Diesel Combustion to Achieve Zero Nox and Particulate Emissions," SAE Technical Paper 2002-01-1744, 2002, doi.

17. Hardy, W.L., and Reitz, R.D., "A Study of the Effects of High Egr, High Equivalence Ratio, and Mixing Time on Emissions Levels in a Heavy-Duty Diesel Engine for Pcci Combustion," SAE Technical Paper 2006-01-0026, 2006, doi.

18. Torregrosa, A.J., Broatch, A., García, A., and Mónico, L.F., "Sensitivity of Combustion Noise and Nox and Soot Emissions to Pilot Injection in Pcci Diesel Engines." Appl. Energy 104(0):149-157, 2013, doi: http://dx.doi.org/10.1016/j.apenergy.2012.11.040.

19. Machrafi, H., Cavadias, S., and Amouroux, J., "A

Parametric Study on the Emissions from an Hcci Alternative Combustion Engine Resulting from the Auto-Ignition of Primary Reference Fuels." Appl. Energy 85(8):755-764, 2008, doi: http://dx.doi.org/10.1016/j.apenergy.2008.02.005.

$20 . \quad$ Okude, K., Mori, K., Shiino, S., and Moriya, T., "Premixed Compression Ignition (Pci) Combustion for Simultaneous Reduction of Nox and Soot in Diesel Engine," SAE Technical Paper 2004-011907, 2004, doi: 10.4271/2004-01-1907.

21. Noehre, C., Andersson, M., Johansson, B., and Hultqvist, A., "Characterization of Partially Premixed Combustion," SAE Technical Paper 2006-01-3412, 2006, doi: 10.4271/2006-01-3412. 22. Kimura, S., Aoki, O., Ogawa, H., Muranaka, S., et al., "New Combustion Concept for Ultra-Clean and High-Efficiency Small Di Diesel Engines," SAE Technical Paper 1999-01-3681, 1999, doi: 10.4271/1999-01-3681.

23. Kimura, S., Aoki, O., Kitahara, Y., and Aiyoshizawa, E., "Ultra-Clean Combustion Technology Combining a Low-

Temperature and Premixed Combustion Concept for Meeting Future Emission Standards," SAE Technical Paper 2001-01-0200, 2001, doi: 10.4271/2001-01-0200.

24. Kalghatgi, G.T., Risberg, P., and Ångström , H.,

"Advantages of Fuels with High Resistance to Auto-Ignition in LateInjection, Low-Temperature, Compression Ignition Combustion," SAE Technical Paper 2006-01-3385, 2006, doi: 10.4271/2006-01$\underline{3385}$.

25. Kalghatgi, G., Risberg, P., and Ångström, H., "Partially Pre-Mixed Auto-Ignition of Gasoline to Attain Low Smoke and Low Nox at High Load in a Compression Ignition Engine and Comparison with a Diesel Fuel," SAE Technical Paper 2007-01-0006, 2007, doi: 10.4271/2007-01-0006.

$26 . \quad$ Hildingsson, L., Kalghatgi, G., Tait, N., Johansson, B., et al., "Fuel Octane Effects in the Partially Premixed Combustion 
Regime in Compression Ignition Engines," SAE Technical Paper 2009-01-2648, 2009, doi: 10.4271/2009-01-2648.

27. Manente, V., Johansson, B., Tunestal, P., and Cannella, W., "Effects of Different Type of Gasoline Fuels on Heavy Duty Partially Premixed Combustion." SAE Int. J. Engines 2(2):71-88, 2010, doi: $\underline{10.4271 / 2009-01-2668 .}$.

28. Lewander, M., Johansson , B., and Tunestål, P., "Investigation and Comparison of Multi Cylinder Partially Premixed Combustion Characteristics for Diesel and Gasoline Fuels," SAE Technical Paper 2011-01-1811; 2011-01-1811, 2011, doi: 10.4271/2011-01-1811.

29. Solaka, H., Aronsson, U., Tuner, M., and Johansson, B., "Investigation of Partially Premixed Combustion Characteristics in Low Load Range with Regards to Fuel Octane Number in a LightDuty Diesel Engine," SAE Technical Paper 2012-01-0684, 2012, doi: $\underline{10.4271 / 2012-01-0684}$.

30. Borgqvist, P., Tunestal, P., and Johansson, B., "Gasoline Partially Premixed Combustion in a Light Duty Engine at Low Load and Idle Operating Conditions," SAE Technical Paper 2012-010687, 2012, doi: 10.4271/2012-01-0687.

31. Kaiadi, M., Johansson, B., Lundgren, M., and Gaynor, J.A., "Sensitivity Analysis Study on Ethanol Partially Premixed

Combustion." SAE Int. J. Engines 6(1, 2013, doi: 10.4271/2013-01$\underline{0269}$.

32. Manente, V., Tunestal, P., and Johansson, B., "Effects of Ethanol and Different Type of Gasoline Fuels on Partially Premixed Combustion from Low to High Load," SAE Technical Paper 201001-0871, 2009, doi: 10.4271/2010-01-0871.

33. Weall, A., and Collings, N., "Gasoline Fuelled Partially Premixed Compression Ignition in a Light Duty Multi Cylinder Engine: A Study of Low Load and Low Speed Operation," SAE Technical Paper 2009-01-1791, 2009, doi: 10.4271/2009-01-1791. 34. Das Adhikary, B., Ra, Y., Reitz, R., and Ciatti, S., "Numerical Optimization of a Light-Duty Compression Ignition Engine Fuelled with Low-Octane Gasoline," SAE Technical Paper 2012-01-1336, 2012, doi: 10.4271/2012-01-1336.

35. Das Adhikary, B., Reitz, R., and Ciatti, S., "Study of inCylinder Combustion and Multi-Cylinder Light Duty Compression Ignition Engine Performance Using Different Ron Fuels at Light Load Conditions," SAE Technical Paper 2013-01-0900, 2013, doi: 10.4271/2013-01-0900.

36. Ciatti, S., Johnson, M., Das Adhikary, B., Reitz, R., et al., "Efficiency and Emissions Performance of Multizone Stratified Compression Ignition Using Different Octane Fuels," SAE Technical Paper 2013-01-0263, 2013, doi: 10.4271/2013-01-0263.

37. Hanson, R., Splitter, D., and Reitz, R., "Operating a HeavyDuty Direct-Injection Compression-Ignition Engine with Gasoline for Low Emissions," SAE Technical Paper 2009-01-1442, 2009, doi: $\frac{10.4271 / 2009-01-1442 .}{38 .}$

$38 . \quad$ Sellnau, M., Sinnamon, J., Hoyer, K., and Husted, H., "Gasoline Direct Injection Compression Ignition (Gdci) - Diesel-Like Efficiency with Low Co2 Emissions," SAE Technical Paper 201101-1386, 2011, doi: 10.4271/2011-01-1386.

39. Sellnau, M.C., Sinnamon, J., Hoyer, K., and Husted, H., "Full-Time Gasoline Direct-Injection Compression Ignition (Gdci) for High Efficiency and Low Nox and Pm." SAE Int. J. Engines 5(2, 2012, doi: 10.4271/2012-01-0384.

40. Sellnau, M.C., Sinnamon, J., Hoyer, K., Kim, J., et al., "Part-Load Operation of Gasoline Direct-Injection Compression Ignition (Gdci) Engine," SAE Technical Paper 2013-01-0272, 2013, doi: $10.4271 / 2013-01-0272$.

41. Benajes, J., Molina, S., Novella, R., and De Lima, D., "Implementation of the Partially Premixed Combustion Concept in a 2-Stroke Hsdi Diesel Engine Fueled with Gasoline." Appl. Energy

Page 15 of 16
122(0):94-111, 2014, doi: http://dx.doi.org/10.1016/j.apenergy.2014.02.013.

42. Benajes, J., Novella, R., Martín, J., and De Lima, D., "Analysis of the Load Effect on the Partially Premixed Combustion Concept in a 2-Stroke Hsdi Diesel Engine Fueled with Conventional Gasoline," SAE Technical Paper 2014-01-1291, 2014, doi: 10.4271/2014-01-1291.

43. Kolodziej, C.P., Ciatti, S., Vuilleumier, D., Das Adhikary, B., et al., "Extension of the Lower Load Limit of Gasoline Compression Ignition with 87 Aki Gasoline by Injection Timing and Pressure," SAE Technical Paper 2014-01-1302, 2014, doi: 10.4271/2014-01-1302.

$44 . \quad$ Benajes, J., Novella, R., De Lima, D., and Tribotté, P., "Analysis of Combustion Concepts in a Newly Designed 2-Stroke Hsdi Compression Ignition Engine." Int. J. Engine Res. (Special Issue Article):1-16, 2014, doi: 10.1177/1468087414562867.

45. Kaiadi, M., Johansson, B., Lundgren, M., and Gaynor, J.A., "Experimental Investigation on Different Injection Strategies for Ethanol Partially Premixed Combustion," SAE Technical Paper 2013-01-0281, 2013, doi: 10.4271/2013-01-0281.

46. Pohorelsky, L., Brynych, P., Macek, J., Vallaude, P.-Y., et al., "Air System Conception for a Downsized Two-Stroke Diesel Engine," SAE Technical Paper 2012-01-0831, 2012, doi: 10.4271/2012-01-0831.

$47 . \quad$ Payri, R., Salvador, F.J., Gimeno, J., and Bracho, G., "A New Methodology for Correcting the Signal Cumulative Phenomenon on Injection Rate Measurements." Exp. Tech. 32(1):4649, 2008, doi: 10.1111/j.1747-1567.2007.00188.x.

48. Payri, R., García, J.M., Salvador, F., and Gimeno, J., "Using Spray Momentum Flux Measurements to Understand the Influence of Diesel Nozzle Geometry on Spray Characteristics." Fuel 84(5):551-561, 2005, doi: 10.1016/j.fuel.2004.10.009.

49. Olsen, D., Hutcherson, G., Wilson, B., and Mitchell, C., "Development of the Tracer Gas Method for Large Bore Natural Gas Engines: Part 1 - Method Validation." J. Eng. Gas Turbines Power 124(3):678-685, 2002, doi: 10.1115/1.1454116.

50. Olsen, D., Hutcherson, G., Wilson, B., and Mitchell, C., "Development of the Tracer Gas Method for Large Bore Natural Gas Engines: Part 2 - Measurement of Scavenging Parameters." J. Eng. Gas Turbines Power 124(3):686-694, 2002, doi: 10.1115/1.1454117. 51. Austen, A.E.W., and Priede, T., "Origins of Diesel Engine Noise," Proc. IMechE Symp. on Engine Noise and Noise Suppression pp 19-32, 1958, doi.

52. Payri, F., Torregrosa, A.J., Broatch, A., and Monelletta, L., "Assessment of Diesel Combustion Noise Overall Level in Transient Operation." Int. J. Automot. Technol. 10(6):761-769, 2009, doi: 10.1007/s12239-009-0089-y.

53. Torregrosa, A.J., Broatch, A., Martín, J., and Monelletta, L., "Combustion Noise Level Assessment in Direct Injection Diesel Engines by Means of in-Cylinder Pressure Components." Meas. Sci. Technol. 18(7):2131-2142, 2007, doi: 10.1088/0957-0233/18/7/045. 54. Dukowicz, J.K., "A Particle-Fluid Numerical Model for Liquid Sprays." J. Comput. Phys. 35(2):229-253, 1980, doi: 10.1016/0021-9991(80)90087-X.

55. Beale, J.C., and Reitz, R.D., "Modeling Spray Atomization with the Kelvin-Helmholtz/Rayleigh-Taylor Hybrid Model."

Atomization Sprays 9(6):623-650, 1999, doi:

10.1615/AtomizSpr.v9.i6.40

56. Han, Z., and Reitz, R.D., "A Temperature Wall Function Formulation for Variable-Density Turbulent Flows with Application to Engine Convective Heat Transfer Modeling." Int. J. Heat Mass Transfer 40(3):613-625, 1997, doi: 10.1016/0017-9310(96)00117-2. 57. Brakora, J.L. "A Comprehensive Combustion Model for Biodiesel-Fueled Engine Simulations." PhD Dissertation, University of Wisconsin-Madison, 2012. 
58. Hiroyasu, H., and Kadota, T., "Models for Combustion and Formation of Nitric Oxide and Soot in Direct Injection Diesel

Engines," SAE Technical Paper 760129, 1976, doi: 10.4271/760129.

59. Nagle, J., and Strickland-Constable, R., "Oxidation of

Carbon between 1000-2000 C," Proceedings of the Fifth Carbon

Conference 1962.

60. Musculus, M.P.B., Miles, P.C., and Pickett, L.M.,

"Conceptual Models for Partially Premixed Low-Temperature Diesel

Combustion." Prog. Energy Combust. Sci. 39(2-3):246-283, 2013,

doi: http://dx.doi.org/10.1016/j.pecs.2012.09.001.

61.

\section{Contact Information}

Dr. RICARDO NOVELLA

CMT - Motores Térmicos - Universitat Politècnica de València

Camino de Vera $\mathrm{s} / \mathrm{n}^{\circ}$ - 46022 Valencia (Spain)

Tel: (0034) 963877650 (76544) Fax: (0034) 963877659

Email: rinoro@mot.upv.es

\section{Acknowledgments}

The authors would like to thank RENAULT SAS for all the technical support provided to perform the research activities.

The authors want also to express their gratitude to CONVERGENT SCIENCE Inc. and IGNITE3D Engineering GmbH for their kind support for performing the CFD calculations using CONVERGE software.

\section{Definitions/Abbreviations}

aTDC

$(\mathbf{A} / \mathbf{F})_{\mathrm{St}}$

CA10, CA50,

CA90

CAD

CDC

CI

CoV P max

CoV IMEP

CR

DOHC

$\Delta \mathbf{P}$

EGR

EVC

EVO

HCCI

HSDI

Page 16 of 16
Conventional diesel combustion

Compression ignition

Coefficient of variation of maximum cylinder pressure

Coefficient of variation of indicated mean effective pressure

Compression ratio

Double overhead camshaft

Pressure difference between intake and exhaust ports

Exhaust Valve Closing (angle)

Exhaust Valve Opening (angle)

Homogeneous Charge Compression Ignition

High Speed Direct Injection
Exhaust Gas Recirculation
IGR

IMEP

IVC

IVO

ISFC

ISFC $_{\text {corr }}$

LHV

MON

Olap

Pint

dP/damax

PPC

PPCI

Prail $_{\text {ra }}$

$\phi$

$\phi$ eff

RoHR

RON

SoC

SoE

SoI

TDC

TIVC

VVA

$\operatorname{VVT}_{(1,2)}$

$\mathrm{YO}_{2, \mathrm{IVC}}$

Indicated Mean Effective Pressure

Intake Valve Closing (angle)

Intake Valve Opening (angle)

Indicated specific fuel consumption

Corrected indicated specific fuel consumption

Lower heating value

Motor Octane Number

Overlap

Intake pressure

Maximum pressure gradient

Partially Premixed Combustion

Partially Premixed Compression Ignition

Injection rail pressure

In-cylinder equivalence ratio

In-cylinder effective equivalence ratio

Rate of Heat Release

Research Octane Number

Start of combustion

Start of energizing (injector signal)

Start of injection

Top Dead Centre

Mean gas temperature at intake valve closing

Variable Valve Actuation

Variable Valve Timing (intake, exhaust)

Oxygen concentration at the intake valve closing angle

$\eta_{\text {combustion }}$

Combustion efficiency

Indicated efficiency
Internal Gas Recirculation 